\title{
Metabolic fingerprinting of banana passion fruits and its correlation with quorum quenching activity
}

\author{
Leonardo Castellanos $^{\mathrm{a}, \mathrm{b}, *}$, Sandra Judith Naranjo-Gaybor ${ }^{\mathrm{a}, \mathrm{c}}$, Abel M. Forero ${ }^{\mathrm{a}}$, Gustavo Morales ${ }^{\mathrm{a}}$, \\ Erica Georgina Wilson ${ }^{\mathrm{b}}$, Freddy A. Ramos ${ }^{\mathrm{a}}$, Young Hae Choi ${ }^{\mathrm{b}, \mathrm{d}}$ \\ ${ }^{a}$ Universidad Nacional de Colombia - Sede Bogotá - Facultad de Ciencias - Departamento de Química, Carrera 30 \# 45-03, Bogotá, D.C., 111321, Colombia \\ ${ }^{\mathrm{b}}$ Natural Products Laboratory, Institute of Biology, Leiden University, Sylviusweg 72, 2333 BE, Leiden, the Netherlands \\ ${ }^{\mathrm{c}}$ Universidad de las Fuerzas Armadas. ESPE Carrera de Ingeniería Agropecuaria Extensión Santo Domingo, Av. General Rumiñahui s/n, Sangolquí, Ecuador \\ ${ }^{\mathrm{d}}$ College of Pharmacy, Kyung Hee University, 02447, Seoul, Republic of Korea
}

\section{A R T I C L E I N F O}

\section{Keywords:}

Passiflora

Passifloraceae

Polyphenols

Burkholderia and chromobacterium

\begin{abstract}
A B S T R A C T
Banana passion fruit of the Passiflora genus, are commercially cultivated on a small to medium scale, mainly as edible fruits or as components of traditional herbal medicines. This subgenus comprises several species and hybrid specimens that grow readily in the wild. Due to their taxonomical complexity, many of these species have recently been reclassified (Ocampo Pérez and Coppens d'Eeckenbrugge, 2017), and their chemical profile has still to be determined. In this study, an ${ }^{1} \mathrm{H}$ NMR-based platform was applied to the chemical profiling of seven wild species of the Passiflora subgenus, and UHPLC-DAD-MS was additionally used for the identification of phenolic compounds. A total of 59 compounds were detected including $26 \mathrm{O}$ - and $\mathrm{C}$-glycosidated flavonoids and polyphenols, nine organic acids, seven amino acids, GABA, sucrose, glucose, myo-inositol, and five other nonidentified compounds. Two of the identified compounds are the previously undescribed C-glycosyl flavonoids, apigenin-4'-O- $\beta$-glucopyranosyl, $8-C$ - $\beta$-(6"acetyl)-glucopyranoside and apigenin-4-O- $\beta$-glucopyranosyl-8-C- $\beta$ neohesperidoside. These $C$-glycosyl flavonoids were isolated to confirm their proposed structures by NMR and LCMS analysis. The PCA score plots obtained from the ${ }^{1} \mathrm{H}$ NMR data of the studied Passiflora samples showed $P$. cumbalensis and $P$. uribei as the species with the most distinguishable chemical profile. In addition, a correlation analysis using OPLS-DA was conducted between ${ }^{1} \mathrm{H}-\mathrm{NMR}$ data and the quorum quenching activity (QQ) of Chromobacterium violaceum ATCC 31532. This analysis revealed $P$. lehmannii, and $P$. uribei extracts to be the most active, and apigenin-4'-O- $\beta$-glucopyranosyl, $8-C-\beta$-(6"acetyl)-glucopyranoside and apigenin-4-O- $\beta$-glucopyranosyl-8-C- $\beta$-neohesperidoside were identified as possibly responsible for the QQ activity. To confirm this, QQ activity of both compounds was tested against $C$. violaceum ATCC 3153. An inhibition of violacein production of $0.135 \mathrm{mM}(100 \mu \mathrm{g} / \mathrm{mL})$ and $0.472 \mathrm{mM}(300 \mu \mathrm{g} / \mathrm{mL})$ was observed for apigenin-4'-O- $\beta$-glucopyranosyl,8-C- $\beta$ (6"acetyl)-glucopyranoside and apigenin-4-O- $\beta$-glucopyranosyl-8-C- $\beta$-neohesperidoside respectively, while bacterial growth was unaffected in both cases. Furthermore, both compounds showed the ability to inhibit the production of the toxoflavin of the phytopathogen Burkholderia glumae ATCC 33617.
\end{abstract}

\section{Introduction}

Passiflora species are highly appreciated and cultivated for their edible fruit, attractive flowers, and medicinal properties as mild tranquilizers and sedatives, for the treatment of insomnia, hysteria and epilepsy, and antidiabetic activity (Ingale and Hivrale, 2010). There are a number of reviews covering this wide range of bioactivities (Gadioli et al., 2018; Ingale and Hivrale, 2010) as well as their biotechnological applications (Corrêa et al., 2016). The northern Andes of Colombia and
Ecuador are at the center of the Passiflora genus diversity (Ocampo Pérez et al., 2007), but most species have not been chemically characterized. Among them, banana passion fruits (oblong or ovoid berry, banana shape, with coriaceous or soft pericarp, light green color and that turns yellow when ripe), which belong to the subgenus Tacsonia of Passiflora genu, a low-level classification based on phenetic features (Ocampo Pérez and Coppens d'Eeckenbrugge, 2017). They are currently viewed with interest as new edible fruits source, though their large-scale commercialization is limited due to the restriction of their

\footnotetext{
* Corresponding author. Universidad Nacional de Colombia - Sede Bogotá - Facultad de Ciencias - Departamento de Química, Carrera 30 \# 45, Bogotá, D.C., 111321, Colombia.

E-mail address: lcastellanosh@unal.edu.co (L. Castellanos).
} 
growth to certain areas of the Andes in S. America. However, given the existing great diversity of the genus, involving more than 50 species that grow above $2000 \mathrm{~m}$ of altitude and yield fruits with a good reputation in local and overseas markets, their agricultural exploitation could be feasible. This possibility could have an additional socioeconomic impact on this region since it could constitute an interesting alternative as crops for small growers in this poverty and violencestricken region of the high Andes, providing some relief for their dire situation (Ocampo Pérez and Coppens d'Eeckenbrugge, 2017). For this, it is essential to study and profile the major species, providing a basis for the selection of the most suitable.

There are many commercially interesting Passiflora species such as P. mollissima (Kunth) L.H. Bailey (syn. P. tripartita var. Mollissima HolmNiels. \& P. Jørg, Curuba de Castilla), P. tarminiana Coppens \& V.E. Barney (Curuba india), P. cumbalensis (Karst) Harms (the rosy passion fruit), P. pinnatistipula Cav. (tintin) and P. mixta L.F. (Curuba de indio or Curuba de monte). Among them, $P$. mollissima is one of the most appreciated by consumers because of the organoleptic properties of its fruits. Its hydroalcoholic leaf extract has already been approved in Colombia as a mild tranquilizer (Ministerio de la Protección Social de Colombia, 2008). On the other hand, P. tarminiana is preferred as a crop by farmers because of its resistance to anthracnose (Colletotrichum gloeosporioides) (Primot et al., 2005).

Besides their nutritional value as fruit, Passiflora species are also known to have many bioactivities, revealing a potential as functional foods. Recently, antimicrobial properties related to quorum quenching activity has been reported for the $C$-flavonoids present in certain Passiflora species (Brango-Vanegas et al., 2014). Bacteria use quorum sensing (QS) systems to coordinate and synchronize their behavior by regulating a number of processes related to their metabolism as a reaction to different circumstances (Helman and Chernin, 2015). For example, it has been reported that toxoflavin production in Burkholderia spp. Is controlled by a QS system, the production of this phytotoxin being a key pathogenicity factor in rice and rot wilt (J. Kim et al., 2004). The expression of some virulence-related traits depends on QS and particularly many plant-pathogenic bacteria, rely on such systems for their survival in host plants (Barnard et al., 2007).

The chemistry of Passiflora plants has been the target of a considerable number of studies, but given the complexity posed by the bioand chemo-diversity of banana Passiflora these have only been studied partially. In some of the species, flavonoids and triterpenoidal saponins have been found to be the main metabolites and amino acids, while alkaloids and cyanogenic glycosides have also been detected but as minor components (Dhawan et al., 2004; Gadioli et al., 2018; Ingale and Hivrale, 2010). Among the flavonoids present in Passiflora, C-glycosyl type flavonoids are well-known for their strong and diverse bioactivities including antitumoral, hepatoprotective, anti-inflammatory, anti-diabetes, antiviral as well as antibacterial and antifungal activities (Ingale and Hivrale, 2010). They are also known to produce quorum sensing disruption (Brango-Vanegas et al., 2014). The detected saponins, on the other hand, are thought to be associated to natural defense systems in the plant, protecting them from the attack of potential pathogens (Osbourn, 2003) and contributing to their insecticidal, antibiotic, and fungicidal activities. Passiflora saponins have also been reported to have minor antiinflammatory, hypocholesterolemic, xanthine oxidase-inhibiting, antifungal, antiprotozoal, antinociceptive and antitumoural properties (Sparg et al., 2004).

Several Passiflora species have been studied using the conventional bioactivity-guided fractionation approach searching for the specific metabolites that could be related to these alleged bioactivities. Unfortunately, as in many cases, this time-consuming design yielded only a few compounds, in general with less activity than expected according to that exhibited by the plants. These disappointing results, echoed over most natural product studies, decreased the expectations of these products as a potential source of new drugs or leads, posing the need for the development of a more efficient experimental design in terms of its outcome.

A few years ago, such an option appeared in the shape of a new approach based on the idea of acquiring and comparing the whole metabolic profiles of plants, that are considered to reflect mechanisms underlying alleged bioactivities. This approach, which uses bio-chemometric tools was conceived within the systems biology framework, is known as metabolomics and aims at the acquisition and comparison of profiles of the low molecular mass metabolites of plants and other organisms and their correlation with proposed bioactivities, ultimately to select those metabolites which could be associated to them (Inui et al., 2012). The goal of research has thus moved from the often indiscriminate isolation of compounds to the multivariate comparison of metabolic profiles of active and inactive samples (Wu et al., 2016). There are many examples of the efficient application of this approach to the discovery of bioactive compounds. The prioritization of 46 spongeassociated actinomycetes was done using metabolomic analysis by LCHRMS and NMR to identify their distinct chemical profiles, as well as their anti-trypanosomal activity against Trypanosoma brucei TC221showing a half maximal inhibitory concentration (IC50) of $<$ $20 \mu \mathrm{g} / \mathrm{mL}$ (Cheng et al., 2015). In another case, the use of NMR-based metabolomics resulted in the discovery of a prenylated isatin antibiotic produced by Streptomyces sp. MBT28, which was then identified as 7prenylisatin using NMR-based metabolomics (Wu et al., 2015). These studies, among many others, are evidence of the efficiency of metabolomics in facilitating the discovery of unreported bioactive compounds.

Different analytical platforms have been used in metabolomics, the most common being LC-MS and ${ }^{1} \mathrm{H}$ NMR. The advantage of the latter is its high reproducibility and ease of quantification as signal intensity is directly related to the molar concentrations (Smolinska et al., 2012). Additionally, it allows an unbiased analytical approach regarding the chemical structure of compounds to be detected and is characterized by very simple and fast sample preparation methods and high-speed throughput.

The aim of this study was the comparative analysis of the metabolic profiles of Passiflora species collected in the Colombian Andes and the correlation of their chemical profiles with their inhibitory quorum sensing activity. For this, a metabolomics study of the six most representative species from the subgenus of banana passion fruits was conducted. Our strategy included a non-targeted approach using NMR analysis to identify the major compounds (Kim et al., 2010) and LCMS to confirm the identity of $C$-flavonoids (Farag et al., 2016). The quorum quenching activity of crude extracts of Passiflora leaves was tested with the Chomobacterium violaceum ATCC 31532 biosensor, and this information was correlated with the metabolic profiles by means of multivariate data analysis.

\section{Results and discussion}

Samples of Passiflora species were collected in the central and southern regions of the Colombian Andes. Wild types were used instead of cultivated samples which generally are hybrids (Table 1). All samples were identified on the basis of their morphological characteristics by the taxonomist Gustavo Morales and voucher samples were deposited in the collection of the Instituto de Ciencias Naturales - Universidad Nacional de Colombia as reported in Table 1.

In the first stage, an untargeted analysis using ${ }^{1} \mathrm{H}$ NMR chemical profiling was performed to obtain specific fingerprints of the Passiflora selected species and their related compounds. The Leiden Natural Products Laboratory database, the Chenomx NMR Suite 8.2 (Chenomx Inc., Edmonton, Alberta, Canada) database and the Human Metabolome Database (HMDB) were used for the identification of compounds in the extracts. This was complemented by the LCMS analysis of butanol fractions of the plant extracts that provided further information on the phenolic compounds. Correlations between the chemical composition of the plants and their quorum quenching activity were established submitting all this data to MVDA including principal component 
Table 1

Banana passion fruits samples collection data.

\begin{tabular}{|c|c|c|c|}
\hline Species of Passiflora collected & $\begin{array}{l}\text { Number of voucher ICN } \\
\text { collection }^{\mathrm{a}}\end{array}$ & Subgenera (Section/series) & Number of samples \\
\hline $\begin{array}{l}\text { Passiflora mollissima (Kunth) L.H.Bailey } \\
\text { Passiflora tripartita var mollisima (Kunth) Holm-Niels \& P. Jorg (synonym). } \\
\text { (The Plant List, 2013a) }\end{array}$ & COL599223 & Tacsonia (Bracteogama) & 7 \\
\hline $\begin{array}{l}\text { Passiflora tripartita (Juss.) Poir } \\
\text { Passiflora tripartita var tripartita (Kunth) Holm-Niels \& P. Jorg. (synonym) } \\
\text { (The Plant List, 2013b) }\end{array}$ & COL599245 & Tacsonia (Bracteogama) & 1 \\
\hline Passiflora cumbalensis (H. Karst) Harms & COL599225 & Tacsonia (Bracteogama) & 10 \\
\hline Passiflora tarminiana Coppens \& V.E. Barney & COL599247 & Tacsonia (Bracteogama) & 13 \\
\hline Passiflora mixta L.F. & COL599246 & Tacsonia (Tacsonia) & 12 \\
\hline Passiflora pinnatistipula Cav. & COL599224 & Tacsonia (Colombiana/Poggendorffia) & 3 \\
\hline Passiflora uribei L. K. Escobar & & $\begin{array}{l}\text { Tacsonia (Colombiana/ } \\
\text { Fimbriatistipula) }\end{array}$ & 3 \\
\hline Passiflora lehmanni Mast & COL599222 & Passiflora (Tiliaefoliea) & 2 \\
\hline
\end{tabular}

a GPS information for collection sites is given in Table S3.

analysis (PCA), and orthogonal partial least squares (OPLS) analyses.

\subsection{NMR metabolic fingerprint of Passiflora species}

Freeze-dried samples of Passiflora leaves were extracted with $\mathrm{CH}_{3} \mathrm{OH}-d_{4}-\mathrm{KH}_{2} \mathrm{PO}_{4}$ buffer in $\mathrm{D}_{2} \mathrm{O}(1: 1, \mathrm{v} / \mathrm{v})$, in order to obtain a wide range of metabolites that included sugars, amino acids, saponins and flavonoids, as these have been reported to be the major compounds in Passiflora species. The resulting spectra of the Passiflora extracts were analyzed with the Chenomx ${ }^{\mathrm{TM}}$ database, along with our in-house database and literature data. Because of the intense overlapping of proton signals, the identity of the proposed compounds was verified by 2DNMR experiments (J-resolved; ${ }^{1} \mathrm{H}-{ }^{1} \mathrm{H}$-correlated spectroscopy-COSYand heteronuclear multiple bond correlation -HMBC-). The complete NMR data for the identified compounds is presented in the supplementary information (Supp. Table 1, and Supp. Fig. 6-16).

The ${ }^{1} \mathrm{H}$-NMR spectra of the Passiflora extracts proved to be very similar. As can be observed with the example of the $P$. tarminiana extract, the presence of amino acids, carbohydrates, and flavonoids was confirmed (Fig. 1 and in Figure SI-1 supporting information for the other extracts). The main differences between species were observed in the aromatic region, suggesting that the composition of the flavonoids and other phenolics was distinctive between species (Fig. 2).

The analysis of the extracts revealed the presence of nine organic acids, seven amino acids, GABA, sucrose, glucose, myo-inositol and five other unidentified compounds. Their distribution among the studied species is presented as a barcoding of primary metabolites in Fig. 3, and shows that the species exhibiting most diversity were $P$. tarminiana, $P$. cumbalensis, $P$. mollissima and $P$. tripartita (Juss.) Poir (syn. P. tripartita var. Tripartita), while the least complex were those of $P$. uribei L. K. Escobar and P. lehmannii Mast. The latter was included in this study as an outlier in order to compare the chemical composition of Passiflora spp. In two different subgenera. The content of sugars, polyhydroxyalcohols and other compounds was found to be very similar for the seven extracts, but the content of organic acids and amino acids did not show a distinct distribution pattern.

The amino acid content of two species of the Passiflora genus has been reported. Twenty one amino acids have been identified in $P$. incarnata (Gavasheli et al., 1974) and 17 in $P$. edulis seeds, an ingredient of "Tainung No. 1", a passion fruit formulation used in China (Liu et al., 2008). The presence of $\gamma$-aminobutyric acid (GABA) was detected in most of the studied species, including $P$. mollisima, the species that is approved in Colombia as a mild tranquilizer (Ministerio de la Protección Social de Colombia, 2008) and in P. uribei, that appears to be the most abundant source of this compound among the studied samples. It is thought that GABA, that has also been detected in $P$. incarnata, might be responsible for the anxiolytic and sedative properties of
Passion fruit leaf extracts (Elsas et al., 2010), though the extent of its pharmacological significance is still unclear (Elsas et al., 2010; JawnaZboińska et al., 2016). Trigonelline, which was identified in all samples as a minor compound has been associated to neuroprotective, antimigraine, sedative, memory-boosting and hypoglycemic activities (Zhou et al., 2012). All these pharmacological properties have been detected in different Passiflora spp. Extracts and support its traditional medicinal use. The presence of 5-carboxymethyl-2,5-dihydrofuran-2one was unexpected as this compound has only been previously isolated from an unrelated organism, the marine sponge Xestospongia sp. Collected in the island of Viti Levu (Fiji). This compound has been reported to possess a mild cytotoxic activity against P388 murine leukemia cells (Quinoa et al., 1986), and has been identified as a key intermediate in the catechol branch of the $\beta$-ketoadipate pathway for the degradation of many arenes by a variety of organisms including microorganisms (Ribbons and Sutherland, 1994). The microbial origin of this compound can explain the variability in its concentration in some of the examined samples, including those of $P$. caerulea and $P$. incarnata acquired in The Netherlands (results not shown). Finally, considering that saponins have been reported as major compounds in other species of the subgenus Passiflora of the Passiflora genus, i.e., P. edulis var flavicarpa (Serie Incarnatae) (Yoshikawa et al., 2000), P. alata (Serie Quadrangulares) (Reginatto et al., 2004), $P$. quadrangularis (Serie Quadrangulares) and $P$. ligularis (Serie Tiliaefoliae), it is noteworthy that no saponins were detected with these methods in the studied species (unpublished results).

The direct analysis of the content of phenolic compounds in the NMR spectra of the extracts was hindered by the high complexity of the aromatic region, the shifting of ${ }^{1} \mathrm{H}$ NMR signals and the low concentration of some of these compounds. Thus, the main phenolics, including some $C$-glycosyl flavonoids and catechins, had to be isolated from the extracts for their identification. Their chemical shifts in $\mathrm{CH}_{3} \mathrm{OH}-d_{4}$ in buffer $\left(90 \mathrm{mM} \mathrm{KH_{2 }} \mathrm{PO}_{4}\right.$ in $\left.\mathrm{D}_{2} \mathrm{O}\right)$ solvent are presented in Supp. Table 2.

The signals for a $C$-neohesperidoside glycosyl were detected in most of the ${ }^{1} \mathrm{H}-\mathrm{NMR}$ spectra of the Passiflora extracts, except in $P$. mollissima and $P$. mixta samples that showed a very low amount if any. The identification of the $C$-neohesperidoside diglycoside was based on the signals for methyl groups at $0.60 \mathrm{ppm}$ that were assigned to its rhamnose methyl protons. This shift is due to the spatial shielding effect of the A-ring of the flavonoid aglycone when the disaccharide moiety is attached at position C- 6 or C-8. The rotational barrier around the $C$ glycosidic linkage also leads to signal doubling in the NMR spectra, as a result of the presence of two main conformers (Camargo et al., 2012; Larionova et al., 2010).

The LC-MS analysis of flavonoids using MS and MS/MS data proved to be useful for the structural elucidation of both $O$-glycosides and $C$ glycoside flavonoids. This technique has been widely used for flavonoid 

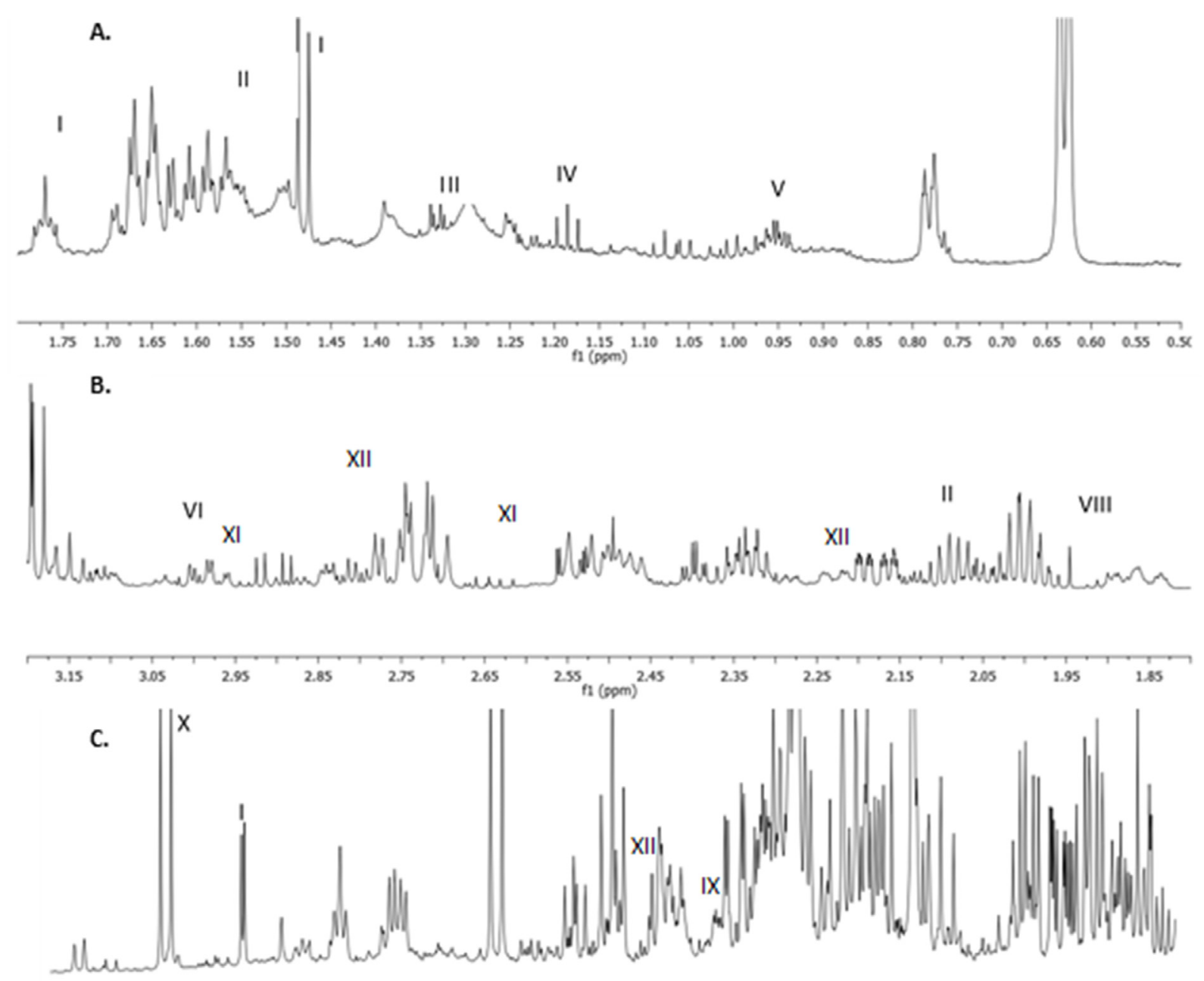

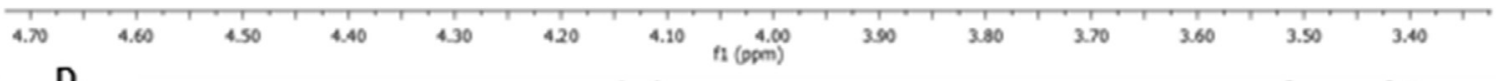

D.

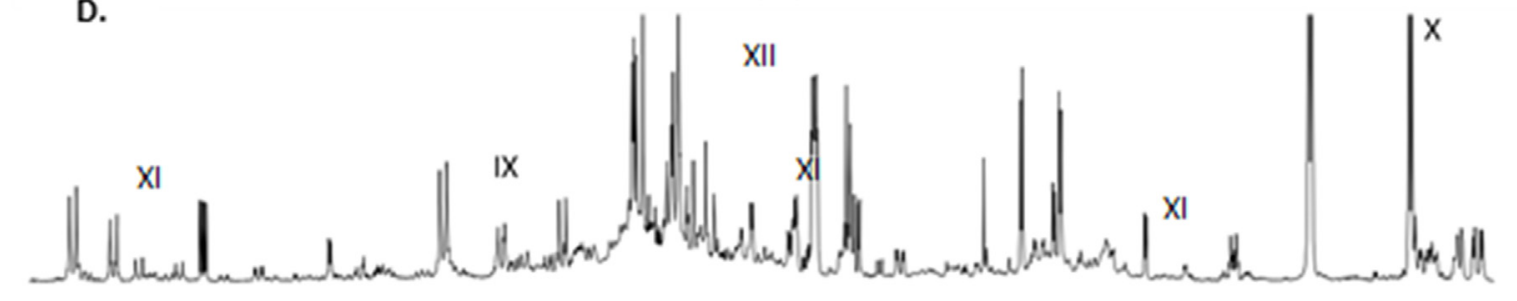

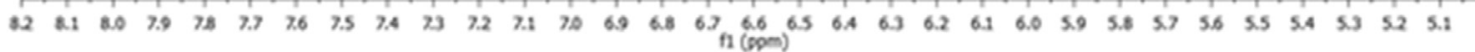

Fig. 1. ${ }^{1} \mathrm{H}$ NMR spectrum of Passiflora leave extract showing aliphatic, sugar and aromatic region and some assignments: ascorbic acid (I), proline (II), threonine (III), ethanol (IV), leucine (V) pipecolic acid (VI) and acetic acid (VIII) (A and B). Sugar region ascorbic acid (I) and glucose (X) (B and C). Phenolic region glucose (X), tyrosine (IX), 5-carboxymethyl-2,5-dihydrofuran-2-one (XI) shikimic acid (XII) (D). The whole NMR signals assignation can be consulted at Table 1 supporting information.

characterization in Passiflora extracts (Farag et al., 2016; Simirgiotis et al., 2013; Zucolotto et al., 2012) In all the studied samples, the BuOH fractions were analyzed by reversed-phase UHPLC-DAD/ESI-2 QToFMS. Peaks were identified by comparison of retention times with those of external standards, mass spectra and UV analysis. The presence of $O$ or $C$ - glycosylation, hexoses, pentoses, and acetyl groups were assigned by the MS/MS data analysis of well-established fragmentation patterns such as $[\mathrm{M}-162]^{+/-}$(hexoses), $[\mathrm{M}-132]^{+/-}$(pentoses), [M-18] ${ }^{+/-}$ and $[\mathrm{M}-120 / 90]^{+/-}$cross-ring cleavages [(O-C1 and $\left.\left.\mathrm{C} 2-\mathrm{C} 3\right)\right]^{\cdot}$ or
[(O-C1 and C3-C4)] for C-hexosides, [M-90/60 ${ }^{+/-}$for $C$-pentosides, and [M-104/74] for C-deoxyhexosides, among other ions, used for flavonoid characterization (Figueirinha et al., 2008). This MS-based approach is useful for positional isomer identification. For example, the differentiation between luteolin-6-C-glucoside (isoorientin, 14) and luteolin-8-C-glucoside (orientin, 16) is based on the high abundance of the product ion at $m / z 429[\mathrm{M}-18-\mathrm{H}]^{-}$in $6-C$-hexoside, which is less intense in 8-C-glucoside (Farag et al., 2016).

In total, 34 phenolics were identified. Supp Table 2 includes the 


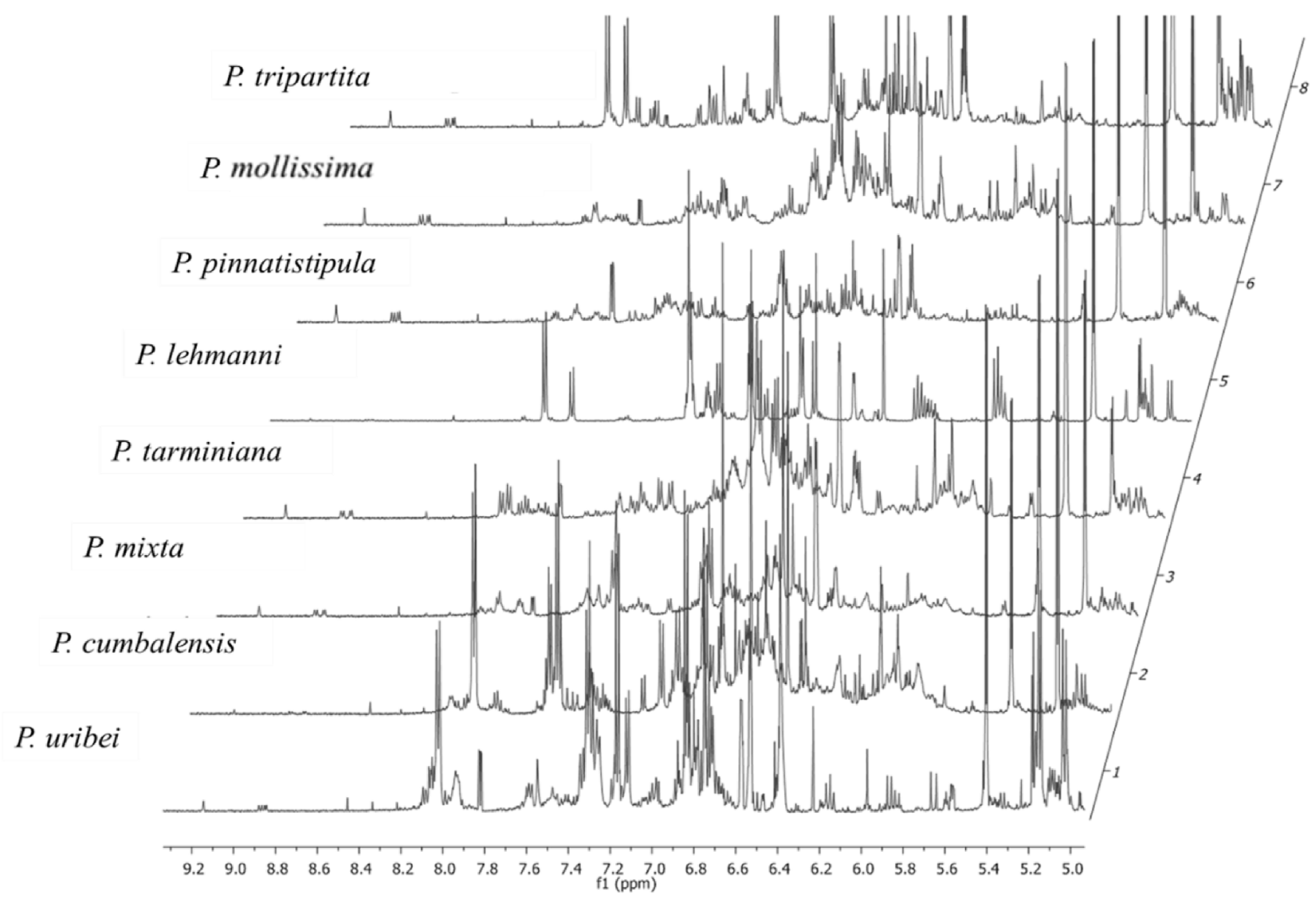

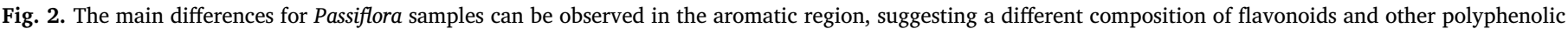
compounds for each species.

NMR data $\left(\mathrm{CH}_{3} \mathrm{OH}-d_{4}\right.$ in buffer $90 \mathrm{mM} \mathrm{KH_{2 }} \mathrm{PO}_{4}$ in $\left.\mathrm{D}_{2} \mathrm{O}\right)$ and retention times, $\mathrm{I}_{\max }$, and experimental $\mathrm{m} / \mathrm{z}$ and MS/MS data obtained by HRMS$\operatorname{ESI}(-)$. Information on NMR data measured in other solvents such as MeOD and DMSO is recorded in Supp. Table 3.

The LC-MS analysis of the $\mathrm{BuOH}$ fraction of Passiflora species (Fig. 4) revealed a wide metabolic diversity in some of the species as shown by the profiles of $P$. tarminiana, $P$. mixta, $P$. tripartita and $P$. mollissima, as well as some less complex profiles such as those of $P$. uribei and $P$. lehmannii extracts, in agreement with their NMR profiles. Interestingly, the profiles of $P$. tripartita and $P$. mollissima showed some significant differences while the profile of $P$. mollisima was similar to that of P. tarminiana (Fig. 4).

The flavonoids identified in the studied samples (Supp. Table 2) included luteolin-derivatives $(10,14-16,20,22-24,28,30,34)$ apigenin-derivatives $(1,2,9,11-13,17-19,21,31)$ and chrysin $(25,27$, 33) aglycones, along with some catechins $(3-5,8)$ and procyanidins $(6$, 7 ). Luteolin derivatives were found to be dominant in $P$. mollissima, but less abundant in $P$. uribei and $P$. mixta. The compound 4'-methoxyluteolin-8-C-6"acetylglucopyranoside (34) described previously by us (Ramos et al., 2010) has been proposed as a chemical marker for $P$. mollissima (Simirgiotis et al., 2013). However, it was found also in $P$. mixta, P. tarminiana and P. uribei. But not in P. tripartita.

Apigenin-related flavonoids have been selected as chemical markers for P. alata by the Brazilian Pharmacopoeia (Farmacopéia, 2010). However, in the studied Passiflora samples, these were detected in all species, except in $P$. cumbalensis extracts, in which chrysin $C$-glycosides were found instead as highly abundant compounds. These chrysin derivatives were also found in $P$. tripartita, and $P$. mixta extracts, but in small quantities. Chrysin had been previously isolated from $P$. caerulea and proposed as an anxiolytic compound (Wolfman et al., 1994). Catechin derivatives were detected in large amounts in $P$. tarminiana and in the two varieties of $P$. tripartita. Interestingly, catechins have also been reported to induce anxiolytic activity (Vignes et al., 2006). However, the biological activity of these particular catechins still has to be determined.

Quorum quenching active butanolic extracts of $P$. lehmannii and $P$. uribei yielded two previously unreported flavonoids, 1 and 2 respectively, as the major compounds. The (-)-HRESIMS spectra of flavonoid 1 of the $P$. lehmannii extract showed an ion at $m / z 635.1624[\mathrm{M}-\mathrm{H}]^{-}$ suggesting a molecular formula of $\mathrm{C}_{29} \mathrm{H}_{32} \mathrm{O}_{16}$. The MS/MS spectrum of the parent ion at $m / z 635$ yielded ions at $m / z 473$ [M-hexose] ${ }^{-}$and 413 [M-H-hexose- $\left.\mathrm{CH}_{3} \mathrm{COO}\right]^{-}$. The ${ }^{1} \mathrm{H}-\mathrm{NMR}$ spectrum (400 MHz, Methanol$\mathrm{d}_{4}$ ) (Supp Fig 6) of this compound showed characteristic signals of apigenin with a monohydroxilated aromatic B ring $\left(\delta_{\mathrm{H}} 8.03,2 \mathrm{H}, \mathrm{d}\right.$, $\left.J=8.4 \mathrm{~Hz} ; \delta_{\mathrm{H}} 7.26,2 \mathrm{H}, \mathrm{d}, J=8.4 \mathrm{~Hz}\right)$, a penta-substituted A ring $\left(\delta_{\mathrm{H}}\right.$ $6.28,1 \mathrm{H}, \mathrm{bs})$ and the characteristic $\mathrm{H}-3$ proton of the $\mathrm{C}$ ring $\left(\delta_{\mathrm{H}} 6.68\right.$, $1 \mathrm{H}, \mathrm{bs})$, along with two $\beta$-anomeric protons $\left(\delta_{\mathrm{H}} 5.04,1 \mathrm{H}, \mathrm{d}, J=7.4 \mathrm{~Hz}\right.$ and $4.99,1 \mathrm{H}, \mathrm{d}, J=10.2 \mathrm{~Hz}$ ). The analysis of the coupling constants showed that both sugar moieties correspond to $\beta$-glucose residues. Assignment of the glucose residues was supported by the HMBC correlation from the glucose protons $\mathrm{H}-1^{\prime \prime}\left(\delta_{\mathrm{H}} 4.96\right)$ and $\mathrm{H}-2^{\prime \prime}\left(\delta_{\mathrm{H}} 4.12\right)$, with the aromatic C-8 carbon at $\delta_{\mathrm{C}} 104.6$, suggesting a $C$-glycosidic bond in the A ring (Supp Fig 8). A similar analysis showed the HMBC correlation from the anomeric proton $\mathrm{H}-1^{\prime \prime \prime}\left(\delta_{\mathrm{H}} 5.03\right)$, with the aromatic carbon C-4' at $\ddot{\mathrm{C}}_{\mathrm{C}} 157.4$, suggesting an $O$-glycosidic bond to the B ring of the flavonoid moiety. The correlation from both $\mathrm{H}-6^{\prime \prime}$ protons at $\delta_{\mathrm{H}} 4.47$ and 4.28 , to the carbon assigned to the acetate carboxyl at $\delta_{\mathrm{C}} 173.1$ suggested the presence of an acetyl group on 6 " of the $C$-glucopyranoside residue (Fig. 5A). Thus, compound 1 was identified as the previously undescribed flavonoid apigenin-4'-O- $\beta$-glucopyranosyl,8- $C$ $\beta$-(6"acetyl)-glucopyranoside. The NMR data are summarized in Table 2. 


\begin{tabular}{|c|c|c|c|c|c|c|c|c|}
\hline COMPOUND & 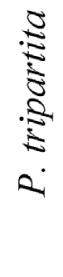 & 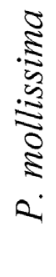 & 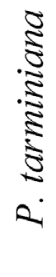 & 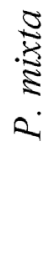 & 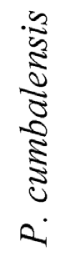 & 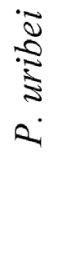 & 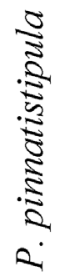 & 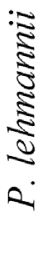 \\
\hline
\end{tabular}

\section{Organic acids}

Acetic acid

Ascorbic acid

Citric acid

Formic acid

Glutamic acid

Malic acid

Pipecolic acid

Shikimic acid

Succinic acid

GABA

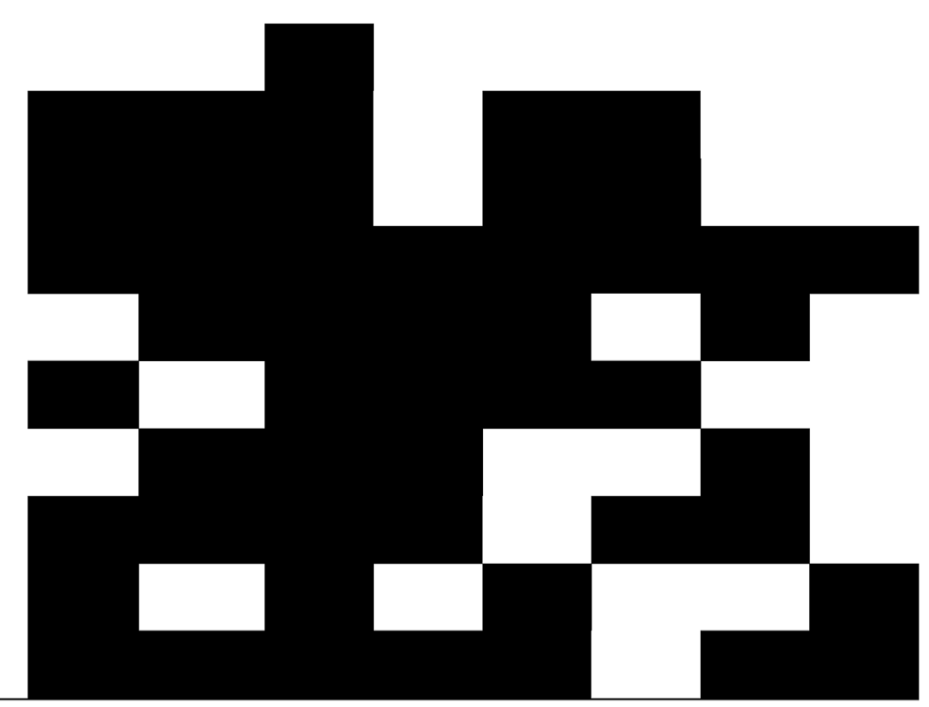

Amino acids

Alanine

Glutamine

Leucine

Proline

Threonine

Tyrosine

Valine

\section{Carbohydrates and polyols}

Glucose

Sucrose

Mio-inositol

\section{Other}

\section{Choline}

Ethanol

Putrescine

Trigonelline

5-carboximetil-2,5-dihidrofuran-2-ona
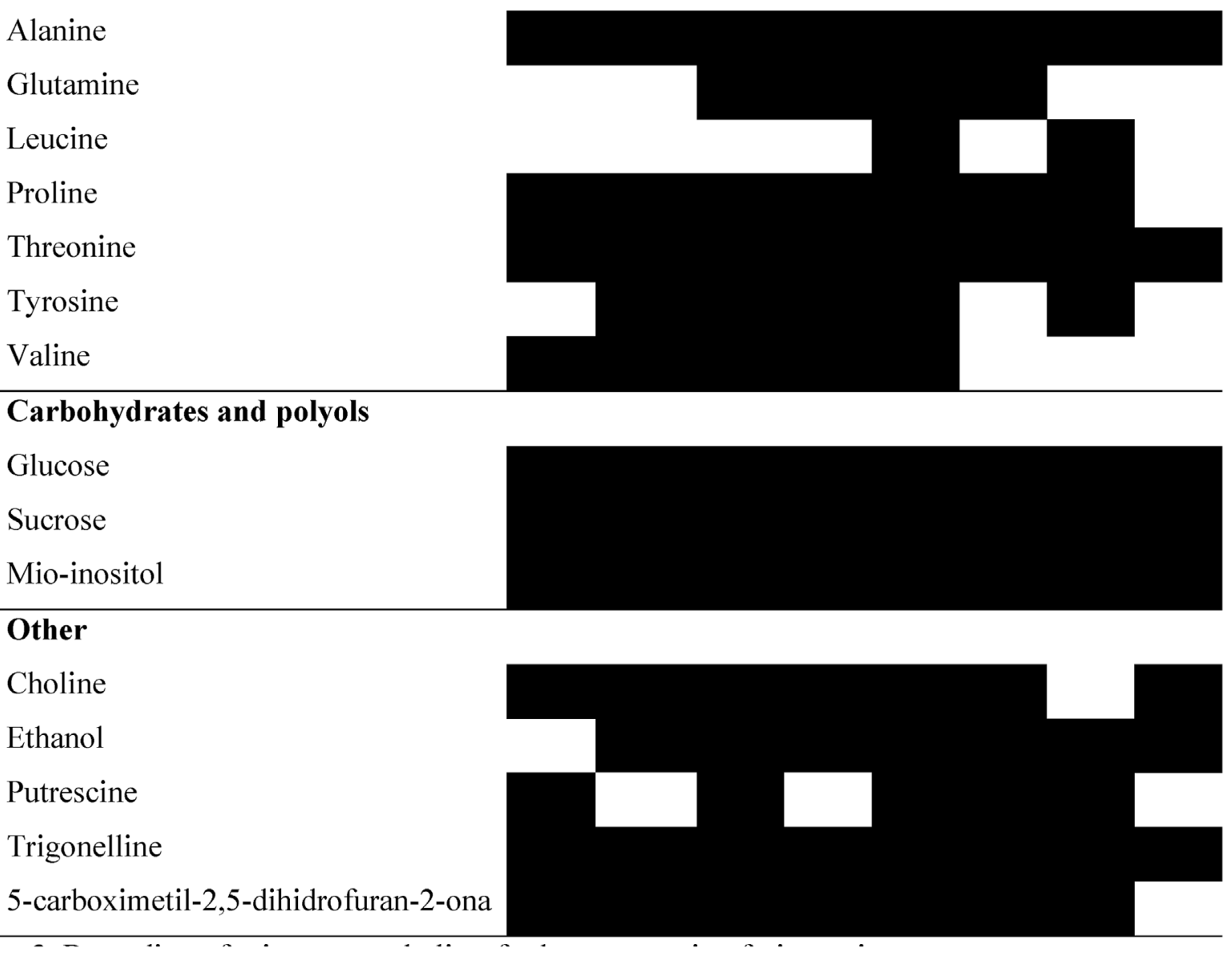

Fig. 3. Barcoding of primary metabolites for banana passion fruit species. 


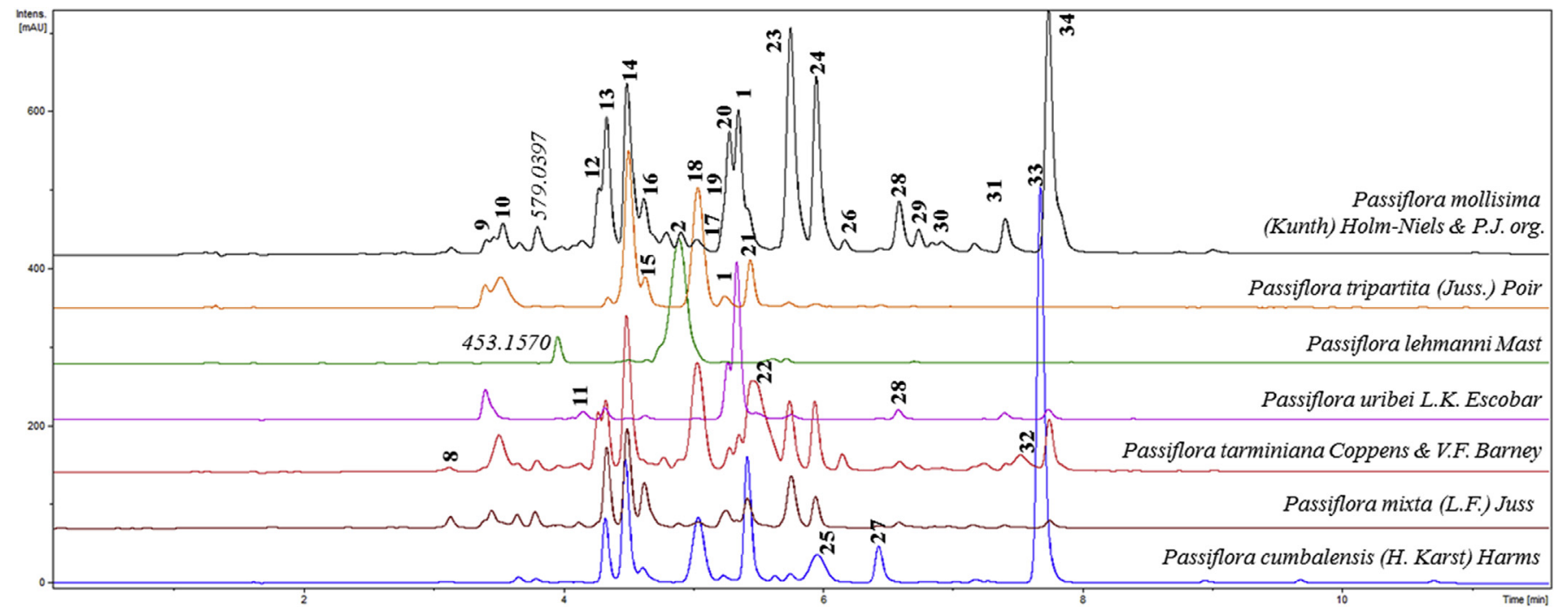

Fig. 4. UHPLC chromatograms ( $340 \mathrm{~nm}$ ) of the butanolic extract of Passiflora species. Bold numbers correspond to identified compounds, and numbers in italics to the $m / z$ of unidentified compounds.

The (-)-HRESIMS spectra of compound 2 yielded an ion at $\mathrm{m} / \mathrm{z}$ $739.2091[\mathrm{M}-\mathrm{H}]^{-}$, corresponding to a possible molecular formula of $\mathrm{C}_{33} \mathrm{H}_{40} \mathrm{O}_{19}$, that together with the ion at $\mathrm{m} / z 413$ [M-hexose-deoxyhexose-H] $]^{-}$obtained with the MS/MS data of the parent ion, suggested the presence of a flavonoid bearing two hexoses and one deoxyhexose residue. The ${ }^{1} \mathrm{H}-\mathrm{NMR}$ data $\left(400 \mathrm{MHz}\right.$, Methanol- $d_{4}$ ) (Supp Fig 11) for this compound, revealed signals that are characteristic of apigenin showing two main conformers with paired signals at $\delta_{\mathrm{H}} 7.97(\mathrm{~d}$, $J=8.7 \mathrm{~Hz})[7.81(\mathrm{~d}, J=8.5 \mathrm{~Hz})] ; 6.93(\mathrm{~d}, J=8.7 \mathrm{~Hz})[6.94(\mathrm{~d}$, $J=8.5 \mathrm{~Hz}$ )] 6.59 (s) [6.62]; 6.27 (s) [6.25 (s)], together with three anomeric protons $\left(\delta_{\mathrm{H}} 5.15(\mathrm{~d}, J=1.3 \mathrm{~Hz})[5.31(\mathrm{~d}, J=1.7 \mathrm{~Hz})] ; 5.03\right.$ (d, $J=9.9 \mathrm{~Hz})[5.15$ (d, $J=9.8 \mathrm{~Hz})] ; 4.39$ (d, $J=7.7 \mathrm{~Hz})[4.27(\mathrm{~d}$, $J=7.9 \mathrm{~Hz}$ )] and a highly overlapping region for the carbinolic protons of the three sugar moieties. The presence of a neohesperidoside moiety was determined by the HMBC (Sup Fig. 11) correlation from the $\alpha$ rhamnopyranosyl anomeric proton at $\delta_{\mathrm{H}} 5.15(\mathrm{~d}, J=1.8 \mathrm{~Hz})[5.31(\mathrm{~d}$, $J=1.7) \mathrm{Hz}] / \delta_{\mathrm{C}} 102.0$ [101.3] to the C-2" $\left(\delta_{\mathrm{C}} 77.6\right.$ [76.7]) of glucopyranoside. The bonding of the neohesperidoside moiety to the carbon $\mathrm{C}-8$ was revealed by the HMBC correlation of the $\beta$-anomeric glucoside proton at $\delta_{\mathrm{H}} 5.03(\mathrm{~d}, J=9.9 \mathrm{~Hz})[5.15(\mathrm{~d}, J=9.8 \mathrm{~Hz})] / \delta_{\mathrm{C}} 73.7$ [75.3], and $\mathrm{H}-2$ " glucopyranose proton at $\delta_{\mathrm{H}} 4.26$ (dd, $J=9.9 ; 8.5$ ) [4.07 (bt, $J=9,3)]$ to the C-8 carbon at $\delta_{\mathrm{C}} 104.7$. The presence of a shielded methyl group at $\delta_{\mathrm{H}} 0.73(\mathrm{~d}, J=6.2)[0.88(\mathrm{~d}, J=6.2)]$ of the rhamnopyranosyl $\mathrm{CH}_{3}-6^{\prime \prime \prime}$ in a $\mathrm{C}-8$ linked neohesperidoside moiety $(\alpha-$ rhamnopyranosyl-( $1 \rightarrow 2)$ - $\beta$-glucopyranoside), due to the strong diamagnetical shift caused by the anisotropic effects of one of the aromatic rings of the apigenin moiety in the preferred conformation of the compound (Larionova et al., 2010). Finally, the position of glycosylation was determined to be C-4' by the HMBC correlation between the anomeric proton at $\delta_{\mathrm{H}} 4.39$ (d, $\left.J=7.44\right)$ [4.27 (d, $J=7.9$ ] and C-4' at $\delta_{\mathrm{C}} 162.7$ as is shown in Fig. 5B. The complete assignment of NMR signals was done using COSY, HSQC and $J$-resolved spectra and are summarized in Table 2 (see supporting information). Compound 2 was thus identified as apigenin-4-O- $\beta$-glucopyranosyl-8- $C$ - $\beta$-neohesperidoside. The presence of this compound in $P$. coactilis had been proposed by Escobar et al., using enzymatic hydrolysis, TLC co-chromatography, $100 \mathrm{MHz}$ NMR and UV analysis for its identification (Escobar et al., 1983). We have now completed this identification with complete NMR and MS data.

\subsection{Taxonomical relationships from the metabolic fingerprint of samples from Passiflora species}

Previous metabolomic studies of Passiflora species showed the presence of $C$ - and $O$-glycosil flavonoids, mandelonitrile glycosides and fatty acid conjugates (Farag et al., 2016; Otify et al., 2015). The barcoding (supporting information Fig. 5) showed that major differences between different species are mostly due to the flavonoid content as well as amino acids.

The PCA-Pareto scaling analysis for the Passiflora extracts yielded four main groups, as depicted by the score plot of PC1 (26.7\%) and PC2 (18.1\%) $\mathrm{R}^{2} 0.652, \mathrm{Q}^{2} 0.421$ (Fig. 6). The only sample that does not belong to the Tacsonia subgenera, P. lehmannii (which belongs to Passiflora subgenera), which was included here as an outlier, unsurprisingly proved to be one of the less related species among the evaluated samples. A highly differentiating pattern was also observed for $P$. uribei
A

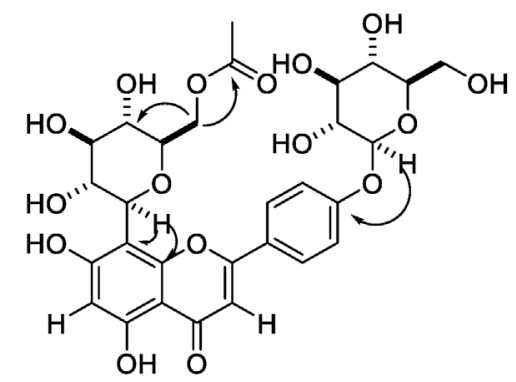

B.

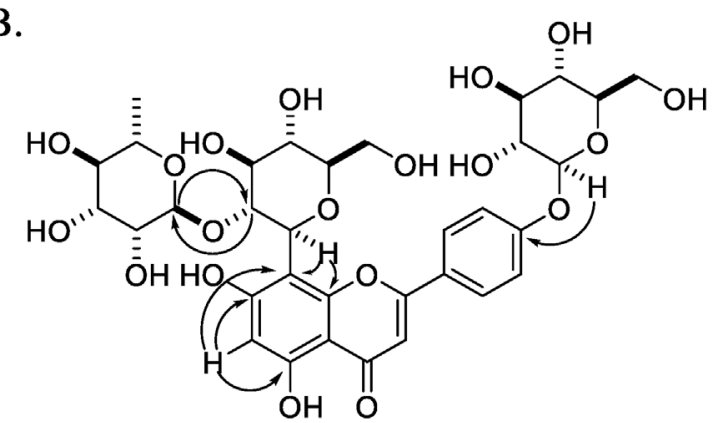

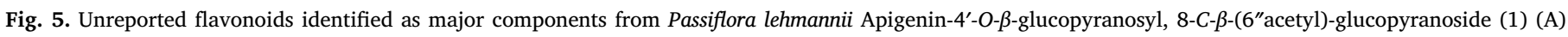
and Passiflora uribei Apigenin-4-O- $\beta$-glucopyranosyl-8-C- $\beta$-neohesperidoside (2) (B). Arrows represent key HMBC correlations. 
Table 2

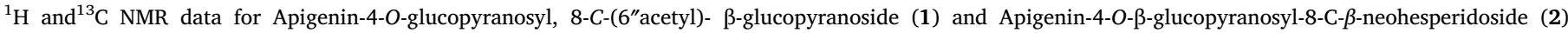
(Methanol- $\mathrm{d}_{4}, \delta$ in ppm, $J$ in $\mathrm{Hz}$ ).

\begin{tabular}{|c|c|c|c|c|}
\hline \multirow[t]{2}{*}{ Position } & \multicolumn{2}{|l|}{ Compound 1} & \multicolumn{2}{|l|}{ Compound 1} \\
\hline & $\delta_{\mathrm{H}}$ (mult, $J$ value in $\mathrm{Hz}$ ) & $\delta_{\mathrm{C}}(\mathrm{ppm})$ & $\delta_{\mathrm{H}}$ (mult, $J$ value in $\mathrm{Hz}$ ) & $\delta_{\mathrm{C}}(\mathrm{ppm})$ \\
\hline 2 & & 165.5 & & $166.6[165.9]$ \\
\hline 3 & 6.68 (bs) & 104.8 & $6.59(\mathrm{~s})[6.62(\mathrm{~s})]$ & $102.0[103.6]$ \\
\hline 4 & & 184.1 & & $184.1[184.4]$ \\
\hline 5 & & 161.1 & & $162.7[162.9]$ \\
\hline 6 & $6.31(\mathrm{~s})$ & 101.8 & $6.27(\mathrm{~s})[6.25(\mathrm{~s})]$ & $99.8[101.3]$ \\
\hline 7 & & 162.8 & & $164.1[164.3]$ \\
\hline 8 & & 104.6 & & $105.3[105.3]$ \\
\hline 9 & & 157.4 & & $157.8[156.4]$ \\
\hline 10 & & 104.8 & & $106.0[105.8]$ \\
\hline $1^{\prime}$ & & 126.4 & & $123.5[123.4]$ \\
\hline $2^{\prime}-6^{\prime}$ & $7.24(\mathrm{~d}, 8.4)$ & 118.1 & $7.97(\mathrm{~d}, 8.7)[7.81(\mathrm{~d}, 8.5)]$ & $130.1[129.6]$ \\
\hline $3^{\prime}-5^{\prime}$ & $8.03(\mathrm{~d}, 8.4)$ & 129.8 & $6.93(\mathrm{~d}, 8.7)[6.94(\mathrm{~d}, 8.5)]$ & $117.0[117.1]$ \\
\hline $4^{\prime}$ & & 161.8 & & $162.7[162.7]$ \\
\hline \multicolumn{5}{|c|}{ C-8 glucose } \\
\hline $1^{\prime \prime}$ & $4.96(d, 9.3)$ & 75.7 & $5.03(\mathrm{~d}, 9.9)[5.15(\mathrm{~d}, 9.8)]$ & $73.7[75.3]$ \\
\hline $2^{\prime \prime}$ & $4.12(t, 9.3)$ & 73.0 & $4.26(\mathrm{dd}, 9.9 ; 8.5)[4.07$ (bt, 9,3)] & $77.6[76.7]$ \\
\hline $3^{\prime \prime}$ & 3.57 (dd, 9.3, 7.9) & 80.2 & $3.68(\mathrm{dd}, 8.5 ; 5.3)[3.73(\mathrm{bt}, 8.7)]$ & $81.6[81.2]$ \\
\hline $4^{\prime \prime}$ & $3.70(\mathrm{~m})$ & 72.5 & $3.65(\mathrm{~m})$ & $72.4[72.4]$ \\
\hline $5^{\prime \prime}$ & $3.67(\mathrm{~m})$ & 80.4 & $3.48(\mathrm{~m})[3.71]$ & $82.8[82.7]$ \\
\hline \multirow[t]{2}{*}{$6^{\prime \prime}$} & $4.47(\mathrm{dd}, 12.0,2.0)$ & 65.2 & $3.97(\mathrm{~m})$ & $62.6[62.3]$ \\
\hline & $4.28(\mathrm{dd}, 12.0 ; 4.7)$ & & $3.80(\mathrm{~m})$ & \\
\hline $\mathrm{CH}_{3} \mathrm{CO}$ & & 173.1 & & \\
\hline $\mathrm{CH}_{3} \mathrm{CO}$ & 1.89 (bs) & 21.0 & & \\
\hline \multicolumn{5}{|c|}{ 4-O-glucose } \\
\hline $1^{\prime \prime \prime}$ & $5.03(\mathrm{~d}, 7.4)$ & 101.6 & $4.39(\mathrm{~d}, 7.7)[4.27(\mathrm{~d}, 7.9)]$ & $105.6[105.2]$ \\
\hline $2^{\prime \prime \prime}$ & $3.48(\mathrm{dd}, 9.6,7.4)$ & 74.9 & $3.17(\mathrm{~m})[3.12(\mathrm{~m})]$ & $75.9[75.9]$ \\
\hline $3^{\prime \prime \prime}$ & $3.40(\mathrm{bt}, 9.4)$ & 71.3 & $3.34(\mathrm{~m})[3.34(\mathrm{~m})]$ & $78.2[78.1]$ \\
\hline $4^{\prime \prime \prime}$ & $3.43(\mathrm{~m})$ & 71.3 & $3.32(\mathrm{~m})$ & $71.3[71.7]$ \\
\hline $5^{\prime \prime \prime}$ & 3.56(m) overlaped & 79.8 & $3.32(\mathrm{~m})$ & $82.8[82.7]$ \\
\hline \multirow[t]{2}{*}{$6^{\prime \prime \prime}$} & $3.73(\mathrm{dd}, 12.0,5.6)$ & 62.5 & $3.79(\mathrm{~m}) / 3.68(\mathrm{~m})[3.79(\mathrm{~m}) / 3.66(\mathrm{~m})]$ & $62.6[62.3]$ \\
\hline & $3.92(\mathrm{dd}, 12.0,2.00)$ & & & \\
\hline \multicolumn{5}{|c|}{ Rhamnose } \\
\hline $1^{\prime \prime \prime}$ & & & $5.13(\mathrm{~d}, 1.8)[5.31(\mathrm{~d}, 1.7)]$ & $102.0[101.3]$ \\
\hline $2^{\prime \prime \prime}$ & & & $3.88(\mathrm{dd}, 3.1,1.8)[3.71(\mathrm{dd}, 3.1,1.7)]$ & $72.0[72.0]$ \\
\hline $3^{\prime \prime \prime}$ & & & $3.59(\mathrm{dd}, 9.6,3.1)[3.24(\mathrm{dd}, 9.4,3.1)]$ & $72.0[71.7]$ \\
\hline $4^{\prime \prime \prime}$ & & & 3.31 (bt, 9.6) $[3.22(b t, 9.4)]$ & $83.2[82.9]$ \\
\hline $5^{\prime \prime \prime}$ & & & $2.55(\mathrm{dq}, 9.6,6.2)[2.11(\mathrm{~m})]$ & $68.3[68.1]$ \\
\hline $6^{\prime \prime \prime}$ & & & $0.73(\mathrm{~d}, 6.2)[0.88(\mathrm{~d}, 6.2)]$ & $18.1[18.1]$ \\
\hline
\end{tabular}

${ }^{a}$ In square bracket the values for less abundant conformer. Abundance 1.00: 0.45 according to ${ }^{1} \mathrm{H}$ NMR.

samples. On the other hand, one of the groups included samples of $P$. mixta, $P$. mollissima and $P$. tarminiana that are species known to hybridize easily, although each one recovers its own morphology and genetic distinctiveness after very few generations, suggesting that they are very close in evolutive terms (Ocampo Pérez and Coppens d'Eeckenbrugge, 2017). This behavior is in agreement with the data obtained from the PCA. The close similarity between $P$. mollissima and $P$. tarminiana suggests that the former could be used alternatively for medicinal purposes as a mild sedative drug. The $P$. cumbalensis samples were grouped apart from others, revealing a slight difference with other Passiflora species as previously reported (Ocampo Pérez and Coppens d'Eeckenbrugge, 2017). This differentiating pattern could be explained by the high contents of chrysin derivatives detected in this study for $P$. cumbalensis (Supp. Table 2 and Fig. 4 and supporting info Fig. 21).

\subsection{Bioprospecting studies of Passiflora species related to $Q Q$ activity}

Having completed the metabolic profiling of the studied Passiflora species, the next step was to relate those profiles with the biological activity observed for the extracts in order to identify the compounds responsible for such an activity (Wu et al., 2015). The selected bioactivity was quorum sensing inhibitory activity (QSI activity) because the search of anti-pathogenic compounds seemed to be a better strategy than the search for antibiotics, in terms of reducing the damage in the host, without generating induced resistance in the pathogen. Several small molecules including $C$-glycoside flavonoids, vanillin, 3-indolyacetonitrile, among others have been reported to be quorum sensing inhibitors (Grandclément et al., 2016), (Brango-Vanegas et al., 2014).

The $\mathrm{MeOH} / \mathrm{H}_{2} \mathrm{O}$ extracts of Passiflora species were tested for the inhibition of violacein production using Chromobacterium violaceum ATCC 31532 as a biosensor (supporting info table 4). Results showed that $P$. uribei, $P$. lehmannii and $P$. cumbalensis exerted a strong activity (inhibition halo $>40 \mathrm{~mm}$ ) (Fig. 17 supporting information) while other Passiflora samples showed less or no activity at all. The complete results are summarized in Supp. Table 4.

The metabolites that had been detected by ${ }^{1} \mathrm{H}-\mathrm{NMR}$ were correlated with the bioactivity (QSI) by applying the orthogonal projection to latent structures (OPLS-DA), using the coded QSI activity (20 mm-inhibition zone was coded as 1 ; > $30 \mathrm{~mm}$ of inhibition zone was coded as 3 ) as the Y-variable. Separation of the active groups is observed in the OPLS-DA score plot $\left(\mathrm{R}^{2}=0.425\right.$ and $\mathrm{Q}^{2}=0.302$, pareto scaling), with the active groups on the negative side along OPLS1 (Fig. 7A). Passiflora cumbalensis clustered as a well-defined active group, while the other species did not show a clear clustering tendency. Three active groups were identified along the OPLS2 axis, one being on the negative side for $P$. lehmannii and $P$. uribei, one on the positive side for $P$. cumbalensis and a third one for the other species spread out in the middle of the plot, suggesting that the active compounds for these three groups were different. 


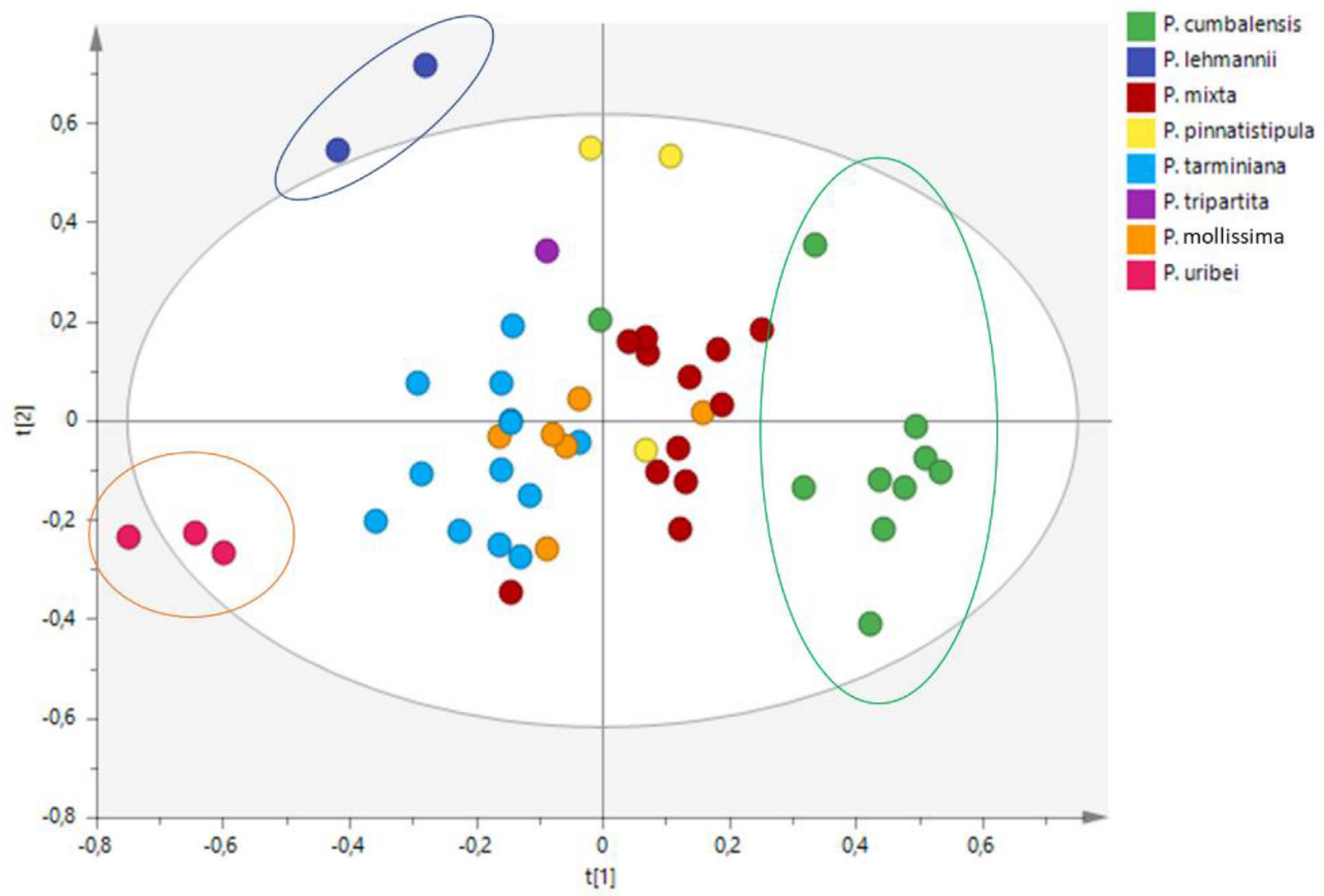

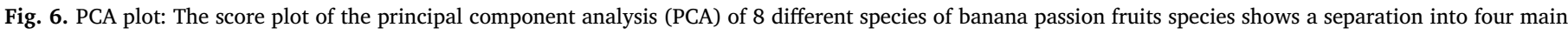
groups.

Using two S-plots, one excluding P. lehmanii samples (Fig. 7B) and the other excluding $P$. cumbalensis samples (Fig. $7 \mathrm{C}$ ) it was possible to identify the active compounds. The variables important for the projection (VIPs) were selected, and the chemical shifts responsible for the QSI activity were highlighted. These highlighted chemical shifts were found to correspond mostly to the glycosylated flavonoids because the signals could be assigned to aromatic protons such as those of the A and $\mathrm{B}$ rings from flavonoids as well as signals for sugar moieties, including those of the anomeric protons close to $5 \mathrm{ppm}$ (Tables 5 and 6, Supporting info).

The quality and robustness of the OPLS-DA model was validated by a permutation test $(n=100)$. The $Q^{2}$ intercept value was -0.504 (below 0.05), showing that the original model was statistically effective (Fig. 18 Supporting info). The model was validated by calculating the area under the receiver operating characteristic (ROC) curve. The value of the area under the curve (AUC) was 0.9565 providing added confidence to the model (Fig. 18B supporting info).

Pure compounds 1 and $\mathbf{2}$ were tested for their QS inhibition against C. violaceum at five concentrations in the range of $50 \mu \mathrm{M}-400 \mu \mathrm{M}$ in a 96 well-plate. The QS inhibition of compound 1 and compound 2 was detected at concentrations of $100 \mu \mathrm{g} / \mathrm{mL}(0.13 \mu \mathrm{mM})$ and $300 \mu \mathrm{g} / \mathrm{mL}$ $(0.47 \mathrm{mM})$ respectively. In order to establish whether the observed inhibition was due solely to QS inhibition and not to growth inhibition, samples were submitted to a growth inhibition test (Fig. 19 supporting information). Results of the assays showed not only the absence of growth inhibition but an increase in bacterial cell densities, indicating that the flavonoids likely inhibited cell communication.

A second model, Burkholderia glumae, a well-known phytopathogen that causes rice grain rot and wilt in various field crops was also used to evaluate QSI (Compant et al., 2008). In B. glumae, the production of toxoflavin (a bright yellow pigment) is known to be one of the major virulence factors (Jeong et al., 2003; J. Kim et al., 2004). The biosynthesis of toxoflavin is controlled by ToxR, a LysR-type transcriptional regulator and this toxin also activates the expression of the tox operons (J. Kim et al., 2004). For this reason, the search for compounds that are able to inhibit toxoflavin production is an important target for the control of this phytopathogen. Two strains were chosen to determine the toxoflavin inhibitory activity of extracts and pure compounds. Burkholderia glumae COK71, is a biosensor strain, that is highly specific for toxoflavin based on $\beta$-galactosidase activity on $\mathrm{X}$ gal substrate that produces a blue pigment, and the B. glumae ATCC 33617 strain as a toxoflavin producer. In this test, the levels of the blue pigment are used to determine toxoflavin inhibitory activity (Choi et al., 2013). Our results indicated that toxoflavin productions was inhibited by concentrations of $6.76 \mu \mathrm{M}$ and $7.87 \mu \mathrm{M}$ of compounds 1 and 2, respectively, while the positive control, 2-n-propyl-9-hydroxy-4H-pyrid [1,2-a] pyrimidin-4-one was active at $80 \mu \mathrm{M}$, showing the potential of these flavonoids to control toxin production by the phytopathogen, $B$. glumae (Fig. 20, supporting information).

The presence of flavonoids in plant extracts has been previously related to their QS inhibition activity. Phytochemical screening of Centella asiatica has revealed that flavonoids can disrupt AHL-mediated QS-controlled systems in C. violaceum and P. aeruginosa while major constituents such as the triterpene, asiatic acid, did not show an anti-QS activity (Vasavi et al., 2016). Concentrations of $100 \mu \mathrm{g} / \mathrm{mL}$ of quercetin and kaempferol have been reported to exhibit anti-QS activity against C. violaceum and P. aeruginosa PAO1. The anti-QS activity of Psidium guajava leaf extract has been determined with a biosensor bioassay using Chromobacterium violaceum CV026, and quercetin and quercetin 3-O-arabinoside were identified as the QQ compounds in the extract, against $C$. violaceum 12,472, at concentrations of 50 and $100 \mu \mathrm{g} / \mathrm{mL}$, respectively (Vasavi et al., 2014). Similarly, Paczkowski et al. studied the QS inhibition mechanism of flavonoids, establishing that they are inhibitors of the QS transcriptional regulator LasR and that they specifically inhibit quorum sensing via antagonism with the transcriptional regulator LasR/RhlR. Further structure-activity relationship analyses suggest that the presence of two hydroxyl moieties in the flavone A-ring backbone are essential for potent inhibition of LasR/RhlR. Biochemical analyses also revealed that flavonoids function non-competitively to prevent LasR/RhlR DNA-binding. The administration of the flavonoids to $P$. aeruginosa was found to alter transcription of the quorum-sensing controlled target promoters and suppress virulence factor production, 

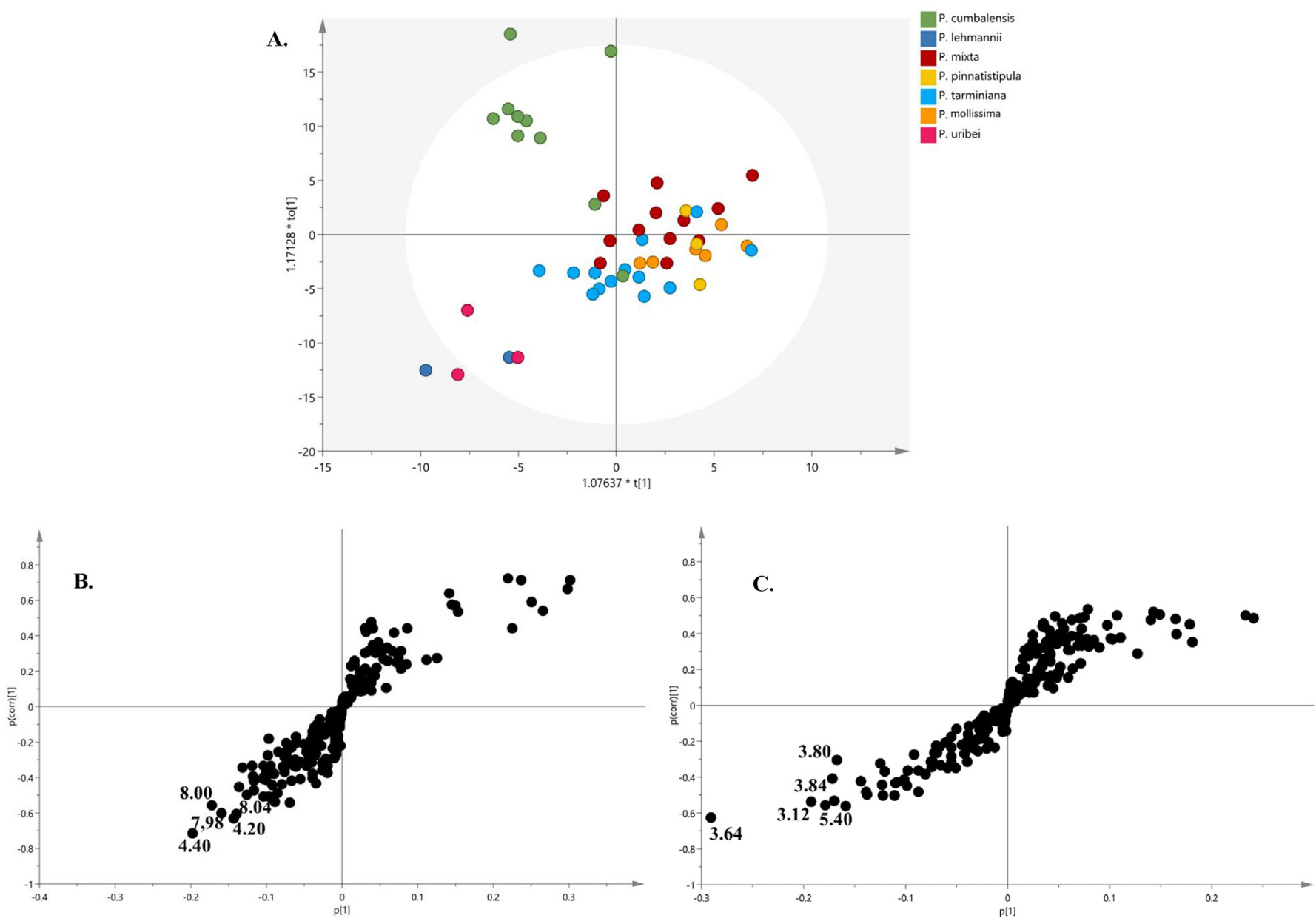

Fig. 7. Supervised multivariate analysis of NMR data. A) OPLS score plot using Y-variable of QSI activity. The plot showed the separation of active and non-active samples along OPLS1 (left side active samples). B) The corresponding $S$-plot significant values for QSI activity without $P$. lehmanii samples. C) The corresponding $S$ plot significant values for QSI activity without $P$. cumbalensis samples.

confirming their potential as antimicrobials which do not function by traditional bactericidal or bacteriostatic mechanisms (Paczkowski et al., 2017).

\section{Conclusion}

Different species of Passiflora subgenus were compared using a metabolomics approach This subgenus includes a group of plants with different biological activities, among which anxiolytic activity is the most prominent. The chemical fingerprinting of seven of the species of this subgenus allowed the identification 59 compounds including amino acids, organic acids, flavonoids and other phenolic compounds. Two previously undescribed flavonoids were identified in $P$. uribei and $P$. lehemanii extracts. Multivariate Data Analysis (PCA and OPLS) of the data of the analyzed species showed $P$. cumbalensis and $P$. uribei to be highly distinguishable species among the other studied species ( $P$. mollisima, $P$. tarminiana, $P$. mixta, and $P$. tripartita). The metabolites that proved to be responsible for these differences were the chrysin glycosides identified in $P$. cumbalensis and acetyl hexoside vitexin present in $P$. uribei. In addition, the flavonoid content was correlated to the quorum sensing inhibitory activity using two types of biosensors, $C$. violaceum and B. glumae. This research contributed to the establishment of metabolic fingerprints for these Passiflora species and their correlation with a biological activity, revealing new potential uses for species of this subgenus. Further chemical studies of the species are required to determine the influence of geographical and environmental conditions on their metabolic profiles.

\section{Materials and methods}

\subsection{General}

Ultrasonicator (Branson 5510 E-MT, Branson Ultrasonics, Danbury, CT, USA), microcentrifuge (Thermo Scientific, Heraeus Pico 17), freezedryer (Edwards Ltd., Crawley, UK). The $600 \mathrm{MHz}\left({ }^{1} \mathrm{H}\right.$ frequency) NMR spectra were recorded on a Bruker spectrometer (DMX-600 spectrometer, Bruker AXS Advanced X-ray Solutions GmbH, Karlsruhe, Germany) operating at a ${ }^{1} \mathrm{H}$ NMR frequency of $600.13 \mathrm{MHz}$ and equipped with a TCI cryoprobe and Z-gradient system. The $400 \mathrm{MHz}$ $\left({ }^{1} \mathrm{H}\right.$ frequency) NMR spectra were recorded on a Bruker spectrometer (Avance 400) operating at a ${ }^{1} \mathrm{H}$ NMR frequency of $400.13 \mathrm{MHz}$. The UHPLC-TOF-MS analyses were performed on an Ultimate 3000 UHPLC system (Thermoscientific, Pittsburgh, PA, USA) coupled to a micro-ToF2Q mass spectrometer from Bruker Daltonics (Bremen, Germany) with an ESI interphase. Silica gel pore size $60 \AA$, 70-230 mesh) for open column chromatography was purchased from Sigma-Aldrich (St. Louis, MO, USA). Sephadex LH-20 (GE Healthcare Life Sciences, Eindhoven, The Netherlands) was used for size-exclusion chromatography.

\subsection{Plant material}

Plants used for this study belonging to the genus Passiflora, family Passifloracea were collected as indicated in Table 1 (more details are provided in Supp. Table 4) and botanically identified according to Escobar, Ocampo and Primot (Primot et al., 2005, Ocampo Pérez and 
Coppens d'Eeckenbrugge, 2017). All studied species (banana passion fruits) belong to Tacsonia subgenus of Passiflora genus. A low-level classification based on phenetic features (Ocampo Pérez and Coppens d'Eeckenbrugge, 2017). A granadilla species, P. lehmannii (subgenus Passiflora, supersection Stipulata Feuillet \& MacDougal) was also collected for comparative purposes. The Central region refers to the Cundinamarca department and the Southern region to Nariño and Huila departments, and altitude and GPS data can be consulted in supplementary information.

All samples consisted of six to ten healthy leaves cut with sterile scissors from mature wild type flowering and fruit-bearing plants. The leaves were frozen immediately with liquid nitrogen and stored at $-80{ }^{\circ} \mathrm{C}$. After grinding in liquid nitrogen, samples were freeze-dried for $48 \mathrm{~h}$, and then extracted with $\mathrm{CH}_{3} \mathrm{OH}-d_{4}$ in buffer $\left(90 \mathrm{mM} \mathrm{KH}_{2} \mathrm{PO}_{4}\right.$ in $\left.\mathrm{D}_{2} \mathrm{O}\right){ }^{1} \mathrm{H}$ NMR analysis.

\subsection{Chemicals and reagents}

Methanol- $d_{4}$, deuterium oxide, and TSP- $d_{4}$ were purchased from Sigma-Aldrich GmbH (Steinheim, Germany). Methanol (AR and Lichrosolv, MerckMillipore), acetonitrile (LCMS grade, Fisher Scientific), formic acid (LCMS grade, Optima, Fisher Scientific), dichloromethane (AR grade) and butanol (AR grade) were purchased from Sigma Aldrich (St. Louis, MO, USA). Reference standards isoorientin $(,>98 \%)$, orientin ( $>97 \%)$, rutin trihydrate $(>95 \%)$, isovitexin (>95\%), vitexin $(,>95 \%)$, and luteolin-7-O-glucoside (, $>98 \%)$ were purchased from Sigma. The identity of the reference compounds was verified by ${ }^{1} \mathrm{H}$ NMR and LC-MS.

\subsection{NMR analysis}

Samples were prepared for metabolomic plant analysis as described by Kim et al., 2010) with slight modifications as described in the supporting information.

\subsection{LC-MS analysis}

For LCMS analysis, $500 \mathrm{mg}$ of dried ground Passiflora leaves were mixed with $5 \mathrm{~mL}$ of water: methanol $(1: 1)$ and sonicated at $25{ }^{\circ} \mathrm{C}$ for $15 \mathrm{~min}$. The extract was filtered and taken to dryness under reduced pressure. The resulting residue was resuspended in water $(5 \mathrm{~mL})$ and extracted subsequently with dichloromethane and butanol. The butanolic fraction was taken to dryness and freeze-dried. Solutions of $1 \mathrm{mg} /$ $\mathrm{mL}$ of the butanolic fraction in water were filtered through $0.20 \mu \mathrm{m}$ disposable membrane filters (Minisart ${ }^{\circledR}$ RC15 Syringe, $0.2 \mu \mathrm{m}$ ). This procedure has been reported to provide flavonoid and saponin-rich butanolic fractions (Zucolotto et al., 2012).

UHPLC-TOF-MS Analysis. Mass spectroscopical analysis was performed on an Ultimate 3000 UHPLC coupled to a Bruker Daltonics microTOF-QII with an ESIsource. In separate runs, detection was done in both positive and negative ion modes. The $\mathrm{m} / \mathrm{z}$ range was 100-1300 Da and the ESI conditions were as follows: nebulizer gas, nitrogen, 2.0 bar; nitrogen drying gas $11 \mathrm{~L} / \mathrm{min}, 200{ }^{\circ} \mathrm{C}$; capillary, $3800 \mathrm{~V}$; end plate offset, $-500 \mathrm{~V}$; funnel $1 \mathrm{RF}, 220 \mathrm{Vpp}$; funnel $2 \mathrm{RF}$, $140 \mathrm{Vpp}$; collision gas, nitrogen; collision energy, $8 \mathrm{eV}$; collision RF 300 Vpp; transfer time, $70 \mu s$; prepulse storage, $5 \mu \mathrm{s}$; spectra rate, $2 \mathrm{~Hz}$. The mass spectrometer was programmed to acquire MS/MS in a data-dependent manner, consisting in five MS/MS scans following each precursor MS1 scan. Similar conditions were used for positive ionization but the capillary voltage was $4000 \mathrm{~V}$. Calibration was performed using a $10 \mathrm{mM}$ sodium formate solution from Sigma-Aldrich (Steinheim, Germany). Samples (3 $\mu \mathrm{L})$ were separated on a Kinetex C18, $150 \times 2.0 \mathrm{~mm}$ column, packed with $2.7 \mu \mathrm{m}$ particles (Phenomenex, USA) at a flow rate of $0.35 \mathrm{~mL} / \mathrm{min}$ using a gradient of $0.5 \%$ aqueous formic acid (solvent A) and acetonitrile/0.5\% formic acid (solvent B), from 17 to $35 \%$ A (0-20 min).

\subsection{Isolation of flavonoids}

Major flavonoids of $P$. cumbalensis, $P$. lehmannii and $P$. uribei detected in the butanolic fractions were isolated using column chromatography, and each fraction was analyzed by LC-MS and NMR; the assigned peaks were used in the analysis of NMR raw extracts spectra (section 4.3). (For details of isolation please consult supporting information).

\subsection{Biological assay}

\subsubsection{Disruption of Chromobacterium violaceum violacein production}

Extracts of Passiflora species were obtained by ultrasonication of $20 \mathrm{mg}$ of freeze-dried powdered leaves with $1.0 \mathrm{~mL}$ of methanol:water (1:1). Mixtures were then centrifuged for $20 \mathrm{~min} 6000 \mathrm{rpm}$, and the supernatants were tested for the presence of QQ compounds using a modified well-diffusion plate assay (Balouiri et al., 2016; McLean et al., 2004). Briefly, a suspension of Chromobacterium violaceum ATCC31532 strain, previously grown in LB liquid medium, was inoculated into $30 \mathrm{~mL}$ of LB agar medium in order to obtain an $\mathrm{OD}_{600 \mathrm{~nm}} 0.5$ suspension. The medium was then poured into $9 \mathrm{~cm}$ agar plates and four wells (6 $\mathrm{mm}$ in diameter) were cut from the agar once it solidified. A $300 \mu \mathrm{L}$ sample of each methanol-water extract was loaded into each well and the plates were incubated for $24 \mathrm{~h}$ at $30^{\circ} \mathrm{C}$. An aliquot of $300 \mu \mathrm{L}$ of $\mathrm{MeOH}: \mathrm{H}_{2} \mathrm{O}(1: 1)$ was used as a negative control and $200 \mu \mathrm{g}$ of 4-hydroxybenzaldehyde (PHB) or kojic acid were used as positive controls. The presence of quorum quenching compounds was detected by the lack of violacein production around the wells without growth inhibition of the biosensor (C. violaceum).

\subsubsection{Burkholderia glumae assays by cross-streaking}

LB agar plates were supplemented with X-gal $(40 \mathrm{mg} / \mathrm{mL})$ and the extract $(0.05 \mathrm{mg} / \mathrm{mL})$ or pure compound $(5 \mu \mathrm{g} / \mathrm{mL}, 6.76 \mu \mathrm{M}$ and $7.87 \mu \mathrm{M}$ for 1 and 2, respectively) to be assayed. An $0.066 \mathrm{mg} / \mathrm{mL}$ $(80 \mu \mathrm{M})$ solution of the quorum quencher 2-n-propyl-9-hydroxy-4Hpyrid [1,2-a] pyrimidin-4-one was used as a positive control. This compound was synthetized according the patent $\mathrm{N}^{\circ} \mathrm{US} 8,507,674 \mathrm{~B} 2$ Aug. 13, 2013 (Suga and Igarashi, 2010). As a negative control, Burkholderia glumae ATCC33617 and B. glumae COK7 were T-streaked onto the same plate with a $5 \mathrm{~mm}$ distance between the tip of both streaks. These strains were previously grown in LB liquid medium, and the suspensions were adjusted to $\mathrm{OD}_{600 \mathrm{~nm}} 0.5$. The presence of toxoflavin induces $\beta$-galactosidase production in strain COK71, developing a blue color. No phenotypic changes were observed in the absence of toxoflavin (Choi et al., 2013). It was thus possible to establish whether the toxoflavin quorum sensing circuit had been quenched by the compounds or extracts The biosensor strain B. glumae COK 71 was kindly donated by Professor Jimwoo Kim of the University of Korea (Choi eta, 2013).

\section{Declaration of competing interest}

The authors declare no conflict of interest.

\section{Acknowledgments}

S.J.N.G. thanks SENESCYT Ecuador for the scholarship grant (2012-2) and ESPE for the leave of absence for doctoral studies. Strains of Burkholderia glumae were kindly provided by the Biotechnology Institute of the Universidad Nacional de Colombia. Chromobacterium violaceum ATCC31532 was kindly provided by Prof. Catalina Arevalo Ferro, Departamento de Biología, Universidad Nacional de Colombia. Burkholderia glumae biosensor (COK 71) was kindly provided by Dr. Jinwoo Kim from Division of Applied Life Science and Institute of Agriculture and Life Sciences, Gyeongsang National University, Republic of Korea. ANLA and Ministerio de Ambiente y Desarrollo 
Sostenible granted permission to collect samples and perform this research ("BIOSPROSPECCION DE ESPECIES DE SOLANUM, PASSIFLORA, PHYSALIS, HYPERICUM, CECROPIA E ILEX", código 38024, resolución 0699 de Abril 26 de 2018, Ministerio de Ambiente y Desarrollo Sostenible) The authors greatly appreciate the financial support provided by the Fondo Nacional de Financiamiento para la Ciencia, la Tecnología y la Innovación, Francisco José de Caldas, contract No. 0459-2013, Red Nacional para la Bioprospección de Frutas Tropicales-RIFRUTBIO.

\section{Appendix A. Supplementary data}

Supplementary data to this article can be found online at https:// doi.org/10.1016/j.phytochem.2020.112272.

\section{References}

Balouiri, M., Sadiki, M., Ibnsouda, S.K., 2016. Methods for in vitro evaluating antimicrobial activity: a review. J. Pharm. Anal. 6, 71-79. https://doi.org/10.1016/j. jpha.2015.11.005.

Barnard, A.M.L., Bowden, S.D., Burr, T., Coulthurst, S.J., Monson, R.E., Salmond, G.P.C., 2007. Quorum sensing, virulence and secondary metabolite production in plant softrotting bacteria. Philos. Trans. R. Soc. B Biol. Sci. 362, 1165-1183. https://doi.org/ 10.1098/rstb. 2007.2042.

Brango-Vanegas, J., Costa, G.M., Ortmann, C.F., Schenkel, E.P., Reginatto, F.H., Ramos, F.A., Arévalo-Ferro, C., Castellanos, L., 2014. Glycosylflavonoids from Cecropia pachystachya Trécul are quorum sensing inhibitors. Phytomedicine 21, 670-675. https://doi.org/10.1016/j.phymed.2014.01.001.

Camargo, L.M.D.M., Férézou, J.-P., Tinoco, L.W., Kaiser, C.R., Costa, S.S., 2012. Flavonoids from Mimosa xanthocentra (Leguminosae: mimosoideae) and molecular modeling studies for isovitexin-2"-O- $\alpha$-l-rhamnopyranoside rotamers. Phytochem. Lett. 5, 427-431. https://doi.org/10.1016/j.phytol.2012.03.015.

Cheng, C., Macintyre, L., Abdelmohsen, U.R., Horn, H., Polymenakou, P.N., Edrada-Ebel, R., Hentschel, U., 2015. Biodiversity, anti-trypanosomal activity screening, and metabolomic profiling of actinomycetes isolated from Mediterranean sponges. PloS One 10, 1-21. https://doi.org/10.1371/journal.pone.0138528.

Choi, O., Lee, Y., Han, I., Kim, H., Goo, E., Kim, J., Hwang, I., 2013. A simple and sensitive biosensor strain for detecting toxoflavin using $\beta$-galactosidase activity. Biosens. Bioelectron. 50, 256-261. https://doi.org/10.1016/j.bios.2013.06.058.

Compant, S., Nowak, J., Coenye, T., Clément, C., Ait Barka, E., 2008. Diversity and occurrence of Burkholderia spp. in the natural environment. FEMS Microbiol. Rev. 32, 607-626. https://doi.org/10.1111/j.1574-6976.2008.00113.x.

Corrêa, R.C.G., Peralta, R.M., Haminiuk, C.W.I., Maciel, G.M., Bracht, A., Ferreira, I.C.F.R., 2016. The past decade findings related with nutritional composition, bioactive molecules and biotechnological applications of Passiflora spp. (passion fruit). Trends Food Sci. Technol. 58, 79-95. https://doi.org/10.1016/j.tifs.2016.10. 006.

Dhawan, K., Dhawan, S., Sharma, A., 2004. Passiflora: a review update. J. Ethnopharmacol. 94, 1-23. https://doi.org/10.1016/j.jep.2004.02.023.

Elsas, S.M., Rossi, D.J., Raber, J., White, G., Seeley, C.A., Gregory, W.L., Mohr, C., Pfankuch, T., Soumyanath, A., 2010. Passiflora incarnata L. (Passionflower) extracts elicit GABA currents in hippocampal neurons in vitro, and show anxiogenic and anticonvulsant effects in vivo, varying with extraction method. Phytomedicine 17, 940-949. https://doi.org/10.1016/j.phymed.2010.03.002.

Escobar, L.K., Liu, Y.-L., Mabry, T.J., 1983. C-glycosylflavonoids from Passiflora coactilis. Phytochemistry 22, 796-797. https://doi.org/10.1016/S0031-9422(00)86995-2.

Farag, M.A., Otify, A., Porzel, A., Michel, C.G., Elsayed, A., Wessjohann, L.A., 2016. Comparative metabolite profiling and fingerprinting of genus Passiflora leaves using a multiplex approach of UPLC-MS and NMR analyzed by chemometric tools. Anal. Bioanal. Chem. 408, 3125-3143. https://doi.org/10.1007/s00216-016-9376-4.

Farmacopéia, 2010. Agência Nacional De Vigilância Sanitária. Farmacopeia Brasileira, $5^{\text {a }}$ edição. 1 Farmacopeia Brasileira.

Figueirinha, A., Paranhos, A., Pérez-Alonso, J.J., Santos-Buelga, C., Batista, M.T., 2008. Cymbopogon citratus leaves: characterization of flavonoids by HPLC-PDA-ESI/MS/MS and an approach to their potential as a source of bioactive polyphenols. Food Chem. 110, 718-728. https://doi.org/10.1016/j.foodchem.2008.02.045.

Gadioli, I.L., da Cunha, M. de S.B., de Carvalho, M.V.O., Costa, A.M., Pineli, L. de L. de O., 2018. A systematic review on phenolic compounds in Passiflora plants: exploring biodiversity for food, nutrition, and popular medicine. Crit. Rev. Food Sci. Nutr. 58, 785-807. https://doi.org/10.1080/10408398.2016.1224805.

Gavasheli, N., Moniava, I., Eristavi, L., 1974. Aminoacids from P. incarnata cultivated in the Georgian SSR. Khimiya Prir. Soedin. (Tashkent) 10, 266.

Grandclément, C., Tannières, M., Moréra, S., Dessaux, Y., Faure, D., 2016. Quorum quenching: role in nature and applied developments. FEMS Microbiol. Rev. 40, 86-116. https://doi.org/10.1093/femsre/fuv038.

Helman, Y., Chernin, L., 2015. Silencing the mob: disrupting quorum sensing as a means to fight plant disease. Mol. Plant Pathol. 16, 316-329. https://doi.org/10.1111/mpp. 12180.

Ingale, A.G., Hivrale, A.U., 2010. Pharmacological studies of Passiflora sp. and their bioactive compounds. Afr. J. Plant Sci. 4, 417-426.
Inui, T., Wang, Y., Pro, S.M., Franzblau, S.G., Pauli, G.F., 2012. Unbiased evaluation of bioactive secondary metabolites in complex matrices. Fitoterapia 83 (7), 1218-1225. https://doi.org/10.1016/j.fitote.2012.06.012.

Jawna-Zboińska, K., Blecharz-Klin, K., Joniec-Maciejak, I., Wawer, A., Pyrzanowska, J., Piechal, A., Mirowska-Guzel, D., Widy-Tyszkiewicz, E., 2016. Passiflora incarnata L. Improves spatial memory, reduces stress, and affects neurotransmission in rats. Phyther. Res. 30, 781-789. https://doi.org/10.1002/ptr.5578.

Jeong, Y., Kim, J., Kim, S., Kang, Y., Nagamatsu, T., Hwang, I., 2003. Toxoflavin produced by Burkholderia glumae causing rice grain rot is responsible for inducing bacterial wilt in many field crops. Plant Dis. 87, 890-895. https://doi.org/10.1094/ PDIS.2003.87.8.890.

Kim, H.K., Choi, Y.H., Verpoorte, R., 2010. NMR-based metabolomic analysis of plants. Nat. Protoc. 5 (3), 536-549. https://doi.org/10.1038/nprot.2009.237.

Kim, J., Kim, J.-G., Kang, Y., Jang, J.Y., Jog, G.J., Lim, J.Y., Kim, S., Suga, H., Nagamatsu, T., Hwang, I., 2004. Quorum sensing and the LysR-type transcriptional activator ToxR regulate toxoflavin biosynthesis and transport in Burkholderia glumae. Mol. Microbiol. 54, 921-934. https://doi.org/10.1111/j.1365-2958.2004.04338.x.

Larionova, M., Spengler, I., Nogueiras, C., Quijano, L., Ramírez-Gualito, K., CortésGuzmán, F., Cuevas, G., Calderón, J.S., 2010. A C-glycosylflavone from piper ossanum, a compound conformationally controlled by $\mathrm{CH} / \pi$ and other weak intramolecular interactions. J. Nat. Prod. 73, 1623-1627. https://doi.org/10.1021/ np100004v.

Liu, S., Yang, F., Li, J., Zhang, C., Ji, H., Hong, P., 2008. Physical and chemical analysis of Passiflora seeds and seed oil from China. Int. J. Food Sci. Nutr. 59, 706-715. https:// doi.org/10.1080/09637480801931128.

McLean, R.J.C., Pierson, L.S., Fuqua, C., 2004. A simple screening protocol for the identification of quorum signal antagonists. J. Microbiol. Methods 58, 351-360. https://doi.org/10.1016/j.mimet.2004.04.016.

Ministerio de la Protección Social de Colombia, 2008. Vademécum Colombiano de Plantas Medicinales. Univ. Nac.

Ocampo Pérez, J., Coppens d'Eeckenbrugge, G., 2017. Morphological characterization in the genus Passiflora L.: an approach to understanding its complex variability. Plant Systemat. Evol. 303, 531-558. https://doi.org/10.1007/s00606-017-1390-2.

Ocampo Pérez, J., Coppens d'Eeckenbrugge, G., Restrepo, M., Jarvis, A., Salazar, M., Caetano, C., 2007. Diversity of Colombian Passifloraceae: biogeography and an updated list for conservation. Biota Colomb. 8, 1-45.

Osbourn, A.E., 2003. Saponins in cereals. Phytochemistry 62, 1-4. https://doi.org/10. 1016/S0031-9422(02)00393-X.

Otify, A., George, C., Elsayed, A., Farag, M.A., 2015. Mechanistic evidence of Passiflora edulis (Passifloraceae) anxiolytic activity in relation to its metabolite fingerprint as revealed via LC-MS and chemometrics. Food Funct 6, 3807-3817. https://doi.org/10. 1039/C5FO00875A.

Paczkowski, J.E., Mukherjee, S., McCready, A.R., Cong, J.-P., Aquino, C.J., Kim, H., Henke, B.R., Smith, C.D., Bassler, B.L., 2017. Flavonoids suppress Pseudomonas aeruginosa virulence through allosteric inhibition of quorum-sensing receptors. J. Biol. Chem. 292, 4064-4076. https://doi.org/10.1074/jbc.M116.770552.

Primot, S., D'Eeckenbrugge, G.C., Rioux, V., Pérez, J.A.O., Garcin, F., 2005. Variación morfológica de tres especies de curubas (Passiflora tripartita var. mollissima, P. tarminiana y P. mixta) y sus híbridos en el Valle del Cauca (Colombia). Rev. Bras. Frutic. 27, 467-471. https://doi.org/10.1590/S0100-29452005000300030.

Quinoa, E., Kho, E., Manes, L.V., Crews, P., Bakus, G.J., 1986. Heterocycles from the marine sponge Xestospongia sp. J. Org. Chem. 51, 4260-4264. https://doi.org/10. 1021/jo00372a029.

Ramos, F.A., Castellanos, L., López, C., Palacios, L., Duque, C., Pacheco, R., Guzmán, A., 2010. An orientin derivative isolated from Passiflora tripartita var. mollissima. Lat. Am. J. Pharm. 29, 141-143.

Reginatto, F.H., Gosmann, G., Schripsema, J., Schenkel, E.P., 2004. Assay of quadranguloside, the major saponin of leaves of Passiflora alata, by HPLC-UV. Phytochem. Anal. 15, 195-197. https://doi.org/10.1002/pca.768.

Ribbons, D.W., Sutherland, A.G., 1994. (+)-Muconolactone from arene biotransformation in Pseudomonas putida: production, absolute configuration and enantiomeric purity. Tetrahedron 50, 3587-3594. https://doi.org/10.1016/S0040-4020(01) 87035-6.

Simirgiotis, M., Schmeda-Hirschmann, G., Bórquez, J., Kennelly, E., 2013. The Passiflora tripartita (banana passion) fruit: a source of bioactive flavonoid C-glycosides isolated by HSCCC and characterized by HPLC-DAD-ESI/MS/MS. Molecules 18, 1672-1692. https://doi.org/10.3390/molecules18021672.

Smolinska, A., Blanchet, L., Buydens, L.M.C., Wijmenga, S.S., 2012. NMR and pattern recognition methods in metabolomics: from data acquisition to biomarker discovery: a review. Anal. Chim. Acta 750, 82-97. https://doi.org/10.1016/j.aca.2012.05.049.

Sparg, S.G., Light, M.E., Van Staden, J., 2004. Biological activities and distribution of plant saponins. J. Ethnopharmacol. 94 (2-3), 219-243. https://doi.org/10.1016/j. jep.2004.05.016.

Suga, H., Igarashi, 2010. Quorum Sensing Inhibitor. Us 20100256369 A1. https://doi. org/10.1126/science.Liquids.

The Plant List, 2013. Passiflora mollissima (kunth) L.H.bailey — the plant list. [WWW Document]. Plant List (2013). Version 1.1. Publ. Internet; (accessed 1st January). http://www.theplantlist.org/. http://www.theplantlist.org/tpl1.1/record/kew2560473 (accessed 12.26.19).

The Plant List, 2013. Passiflora Tripartita (Juss.) Poir. — the Plant List. [WWW Document]. Plant List (2013). Version 1.1. Publ. Internet;. (accessed 1st January). http://www.theplantlist.org/ http://www.theplantlist.org/tpl1.1/record/tro24201478 (accessed 12.26.19).

Vasavi, H.S., Arun, A.B., Rekha, P.-D., 2014. Anti-quorum sensing activity of Psidium guajava L. flavonoids against Chromobacterium violaceum and Pseudomonas aeruginosa PAO1. Microbiol. Immunol. 58, 286-293. https://doi.org/10.1111/1348-0421. 
12150

Vasavi, H.S., Arun, A.B., Rekha, P.D., 2016. Anti-quorum sensing activity of flavonoidrich fraction from Centella asiatica L. against Pseudomonas aeruginosa PAO1. J.

Microbiol. Immunol. Infect. 49, 8-15. https://doi.org/10.1016/j.jmii.2014.03.012. Vignes, M., Maurice, T., Lanté, F., Nedjar, M., Thethi, K., Guiramand, J., Récasens, M., 2006. Anxiolytic properties of green tea polyphenol (-)-epigallocatechin gallate (EGCG). Brain Res. 1110, 102-115. https://doi.org/10.1016/j.brainres.2006.06.062.

Wolfman, C., Viola, H., Paladini, A., Dajas, F., Medina, J.H., 1994. Possible anxiolytic effects of chrysin, a central benzodiazepine receptor ligand isolated from Passiflora coerulea. Pharmacol. Biochem. Behav. 47, 1-4. https://doi.org/10.1016/00913057(94)90103-1.

Wu, C., Choi, Y.H., van Wezel, G.P., 2016. Metabolic profiling as a tool for prioritizing antimicrobial compounds. J. Ind. Microbiol. Biotechnol. 43, 299-312. https://doi. org/10.1007/s10295-015-1666-x.
Wu, C., Du, C., Gubbens, J., Choi, Y.H., Van Wezel, G.P., 2015. Metabolomics-driven discovery of a prenylated isatin antibiotic produced by Streptomyces species MBT28. J. Nat. Prod. 78, 2355-2363. https://doi.org/10.1021/acs.jnatprod.5b00276.

Yoshikawa, K., Katsuta, S., Mizumori, J., Arihara, S., 2000. New cycloartane triterpenoids from Passiflora edulis 1. J. Nat. Prod. 63, 1377-1380. https://doi.org/10.1021/ np000182a.

Zhou, J., Chan, L., Zhou, S., 2012. Trigonelline: a plant alkaloid with therapeutic potential for diabetes and central nervous system disease. Curr. Med. Chem. 19, 3523-3531. https://doi.org/10.2174/092986712801323171.

Zucolotto, S.M., Fagundes, C., Reginatto, F.H., Ramos, F.A., Castellanos, L., Duque, C., Schenkel, E.P., 2012. Analysis of C-glycosyl flavonoids from south American Passiflora species by HPLC-DAD and HPLC-MS. Phytochem. Anal. 23, 232-239. https://doi.org/10.1002/pca.1348. 